\title{
Variability in surface rupture between successive earthquakes on the Suusamyr Fault, Kyrgyz Tien Shan: implications for palaeoseismology
}

\author{
E.A. Ainscoe ${ }^{\oplus},{ }^{1}$ K.E. Abdrakhmatov, ${ }^{2}$ S. Baikulov, ${ }^{2}$ A.S. Carr, ${ }^{3}$ A.J. Elliott, ${ }^{1}$ \\ C. Grützner ${ }^{4}$ and R.T. Walker ${ }^{1}$ \\ ${ }^{1}$ COMET, Department of Earth Sciences, University of Oxford, Oxford OX1 3AN, UK. E-mail: eleanorainscoe@earth.ox.ac.uk \\ ${ }^{2}$ Institute of Seismology, National Academy of Sciences, Bishkek 720060, Kyrgyz Republic \\ ${ }^{3}$ School of Geography, Geology and the Environment, University of Leicester, Leicester LE1 7RH, UK \\ ${ }^{4}$ Institute of Geological Sciences, Friedrich Schiller University Jena, 07749 Jena, Germany
}

Accepted 2018 October 30. Received 2018 September 23; in original form 2018 April 18

\begin{abstract}
SUMMAR Y
Interpretation of surface fault scarps and palaeoseismic trenches is a key component of estimating fault slip rates, earthquake recurrence rates and maximum magnitudes for hazard assessments. Often these analyses rely on the assumption that successive earthquakes all breached the surface and that the ruptures are recorded topographically, or by the deposits exposed in a trench. The $M_{\mathrm{w}} 7.21992$ Suusamyr earthquake, Kyrgyzstan, is an apparently problematic case for such analyses because its ruptures show significant displacement but are only mapped as having broken the surface along small, disparate portions of the fault. Here we present the results of surveys conducted along the Suusamyr Fault to establish whether that is the case. Two sets of ruptures were identified following the earthquake. They are unusually short for their displacement and are separated by a $25 \mathrm{~km}$ gap. Using satellite imagery, high-resolution digital elevation models and palaeoseismic trenching we first reassess the distribution of the 1992 ruptures and then reconstruct the Holocene earthquake record to establish the extent to which the 1992 earthquake is representative of the rupture behaviour of this fault. We find evidence for at least two prehistoric surface rupturing earthquakes in the Holocene: one $\sim 3 \mathrm{ka}$ and one $>8 \mathrm{ka}$ that, along with the modern event, gives recurrence intervals of $\sim 3$ and $\sim 5$ kyr. Within spatial gaps between segments of the 1992 ruptures there are clear prehistoric surface ruptures and the ruptures in each prehistoric earthquake were discontinuous. We conclude that there is significant variability in the surface rupture pattern of successive earthquakes on the Suusamyr Fault, with implications for the completeness of palaeoseismic records obtained from thrust scarps.
\end{abstract}

Key words: Palaeoseismology; Geomorphology; Neotectonics; Earthquake hazards.

\section{INTRODUCTION}

Establishing the seismic history of a region is an important part of seismic hazard assessment. Specifically, information on the magnitudes, dates and locations of past earthquakes can contribute to assessments of the potential magnitude and recurrence frequency of earthquakes that threaten a location (e.g. Youngs et al. 2003; Field et al. 2014; Petersen et al. 2015).

The most direct methods for extending our knowledge of the sizes and dates of past earthquakes are based on identification, measurement and dating of offset Quaternary landforms and sedimentary deposits. The length of an earthquake rupture can be measured directly if its surface rupture trace is sufficiently well preserved. The age and displacement of historic or prehistoric earthquakes can be found by palaeoseismic excavations that expose datable stratigraphic relationships between different faulting events. Conversions from the measured displacement and/or length of a rupture to the corresponding earthquake magnitude rely on empirical scaling relationships that are derived from catalogues of well measured more recent earthquakes whose magnitude is known from seismology or geodesy (Wells \& Coppersmith 1994; Mai \& Beroza 2000; Leonard 2010; Stirling et al. 2013; Anderson et al. 2017).

Uncertainties in the scaling relationships are caused by variability in slip, rupture length and surface rupture length among earthquakes of a given magnitude. Additionally, for the application of scaling relationships to determining the magnitudes of prehistoric earthquakes, a strategy for how to use measurements of surface ruptures must be chosen. For example, typically only a point measurement 
of displacement is available from palaeoseismic trenches, whereas scaling relationships between displacement and magnitude typically refer to the average or maximum displacement of an entire rupture. Statistical methods have been proposed to account for this limited sampling (Hemphill-Haley \& Weldon 1999; Biasi \& Weldon 2006). For studies relating rupture length to magnitude, care must be taken to use scaling relationships that specifically relate the parameters that are observable. While subsurface rupture length bears a more direct and meaningful relationship to earthquake magnitude, surface rupture length is the only proxy for this value available for prehistoric earthquakes. Thus, a proper understanding of the relationship between subsurface rupture length, surface rupture length and magnitude is crucial when interpreting the magnitude of past earthquakes from geomorphology.

Interpretation of prehistoric earthquake ruptures is particularly important for the Tien Shan mountain range in Central Asia (Fig. 1) which was hit by magnitude $>7$ earthquakes in 1887, 1889 and 1911 (Kondorskaya et al. 1982; Kulikova \& Krüger 2015; Krüger et al. 2015). The region has the capacity for more major and damaging earthquakes, as it accommodates $20 \pm 2 \mathrm{~mm} \mathrm{yr}^{-1}$ (Zubovich et al. 2010) of the shortening between India and Eurasia across multiple faults (Thompson et al. 2002). However, due to the recurrence interval on each individual fault typically being several thousand years (Abdrakhmatov et al. 2016; Deev et al. 2016; Landgraf et al. 2016; Grützner et al. 2017; Patyniak et al. 2017), much of what is known about the earthquake history and slip rate of Tien Shan faults comes from palaeoseismic and geomorphic studies (e.g. Thompson et al. 2002).

The $M_{\mathrm{w}} 7.21992$ August 19 Suusamyr earthquake, Kyrgyzstan, is the largest earthquake to have hit the Tien Shan since the 1946 Chatkal earthquake (Kalmetieva et al. 2009; Bindi et al. 2012), and is the only surface rupturing earthquake to have occurred in the Tien Shan in recent decades. Its magnitude, location and overall strike, dip and rake have been well established through modern seismology (Mellors et al. 1997; Gómez et al. 1997). The event is therefore a valuable opportunity to relate the seismological characteristics of earthquake size with their surface rupture characteristics in the Tien Shan. This earthquake rupture is also an illuminating exception to the expectation that earthquake ruptures reach the surface with continuous surface expression in that it showed an extremely discontinuous surface rupture with a total surface rupture length much shorter than the estimated subsurface rupture length, but with a substantial amount of slip reaching the surface at the parts that did break. Aftershocks define a fault plane $50 \pm$ $10 \mathrm{~km}$ long (Mellors et al. 1997), consistent with the magnitude according to scaling relationships (Thingbaijam et al. 2017), and yet only two short, isolated surface rupture sites were found. One showed $\sim 4 \mathrm{~m}$ of surface slip over a length of only $600 \mathrm{~m}$ (A in Fig. 1) and the other was reported as showing up to $1.8 \mathrm{~m}$ vertical displacement over a total length of $3.4 \mathrm{~km}$ (B in Fig. 1; Ghose et al. 1997).

These observations violate the standard approach used in relating palaeoseismological studies to seismic hazard, and illustrate a substantial challenge in using some of the few observations available to assess the magnitudes of past earthquakes. It is therefore critical to understand the nature of surface ruptures from this earthquake and their implications for the continuity of surface slip that would be found in palaeoseismic investigations.

In this paper we use high-resolution satellite imagery and digital elevation models (DEMs) to examine the distribution of surface ruptures from 1992 and to compare their distribution to older palaeoearthquake scarps. We reconstruct the Holocene earthquake record from palaeoseismic trenching. Finally, we discuss the Suusamyr Fault in terms of its implications for palaeoseismic interpretations in general.

\section{THE 1992 SUUSAMYR EARTHQUAKE}

The 1992 August 19 earthquake caused major damage in the Suusamyr region and minor structural damage in Bishkek (Fig. 1a). Shaking reached Modified Mercalli (MM) Intensity X in small areas and was VIII-IX around much of the western Suusamyr basin region (Ghose et al. 1997). Approximately 50 deaths were reported, mostly as a consequence of landsliding, and there was considerable damage from shaking to buildings in the surrounding villages (Ghose et al. 1997).

The main shock was recorded by seismic stations globally and by an analogue regional network. A digital regional network and an additional six temporary local stations recorded aftershocks from 7 and $27 \mathrm{~d}$ after the main shock, respectively (Mellors et al. 1997). Mellors et al. (1997) and Gómez et al. (1997) estimated the focal mechanism from body-wave and surface-wave inversions. The mechanism shows a fault striking east-west $\left(088^{\circ}-100^{\circ}\right)$ and dipping steeply to the south $\left(49^{\circ}-60^{\circ}\right)$, with a reverse sense of slip and a small right-lateral component (rake $105^{\circ}-127^{\circ}$ ). This corresponds to a slip vector pointing to the northwest and a $P$-axis azimuth of approximately $333^{\circ}-359^{\circ}$ - a typical value for the Tien Shan (Ghose et al. 1998). The centroid depth is poorly constrained as $12-17 \mathrm{~km}$, the moment magnitude is listed as $M_{\mathrm{w}} 7.0-7.3$ and directivity studies found that the rupture propagated westward (Gómez et al. 1997; Mellors et al. 1997). Mellors et al. (1997) found that a single-event model fits the observed waveforms well, but that a complex source is possible. The aftershock locations formed a plane dipping to the south from the surface on the southern side of the Suusamyr valley to near the hypocentre at $\sim 18 \mathrm{~km}$ depth. Based on the aftershock zone Mellors et al. (1997) estimated a total rupture length of 50 $\pm 10 \mathrm{~km}$, with the centre around $\sim 73.5-73.6^{\circ} \mathrm{E}$. Three strong aftershocks $\left(M_{\mathrm{s}} 6.6, M_{\mathrm{s}} 6.6\right.$ and $\left.m_{\mathrm{b}} 6.0\right)$ located progressively west of the main shock occurred within the first $2 \mathrm{hr}$ (Mellors et al. 1997; Figs 1 and 2). As two of the relocated aftershock epicentres are to the south of the zone of small aftershocks recorded by the local network, it is possible that the strong aftershock relocations based on teleseismic data may have a southward bias (Mellors et al. 1997)). It was not possible to determine the aftershock focal mechanisms or depths due to sparse teleseismic coverage and interference from main-shock surface waves (Mellors et al. 1997).

Field and helicopter surveys conducted within the year after the earthquake reported that surface ruptures were created at two distinct sites separated by $25 \mathrm{~km}$ (Bogachkin et al. 1997; Ghose et al. 1997). The eastern site is located close to the M41 highway at the eastern end of the Chet-Korumdy Ridge (CKR) - a prominent elongated hill in the valley between the Talas Range and the Aramsu Range (Fig. 1). At this eastern site Ghose et al. (1997) reported a north-facing scarp $500 \mathrm{~m}$ in length, both ends of which displaced the Suusamyr River bed, causing rapids. They reported that the scarp had a 'fold-scarp' morphology, with a maximum vertical displacement of $2.7 \mathrm{~m}$. At a marker that shows convergence they estimated a net slip of $4.2 \pm 0.4 \mathrm{~m}$. They also reported several shorter, smalleroffset scarps in the footwall of the main scarp; they attribute minor north-facing scarps to near-surface splays or to secondary deformation and the south-facing scarps breaking the highway itself as most likely to be on steeply dipping conjugate fault planes (not shown in Fig. 1 because the road has been rebuilt). 


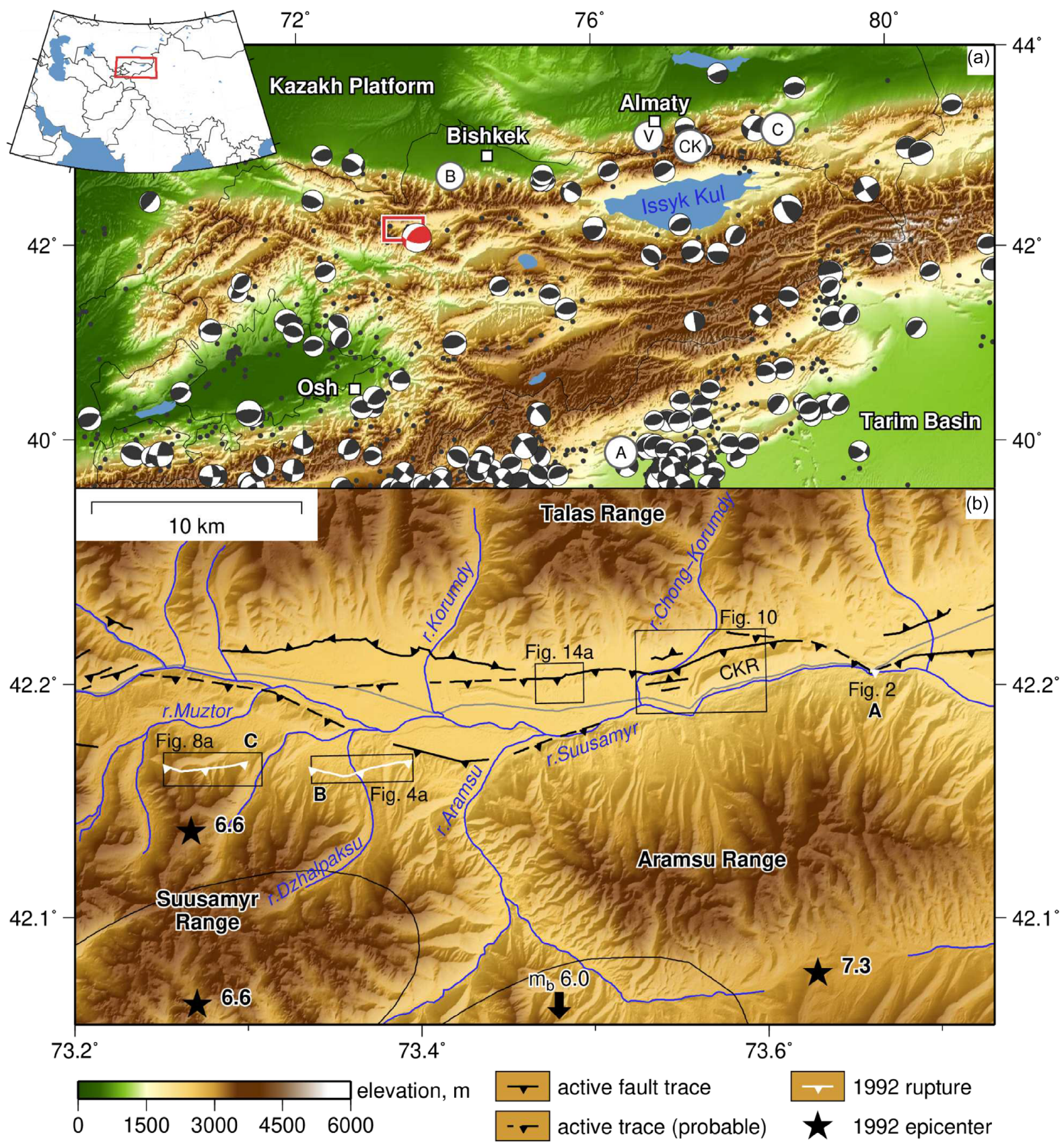

Figure 1. (a) Overview map of the Suusamyr Basin and its situation within the Tien Shan. Red box shows the location of panel (b). Red focal mechanism: Suusamyr earthquake (Mellors et al. 1997). Black focal mechanism: CMT catalogue earthquakes. White dots: Chilik 1889, Chon-Kemin 1911, Verny 1887, Belovodskoe 1885 and Atushi 1902 epicentres (Kondorskaya et al. 1982; Krüger et al. 2015; Kulikova \& Krüger 2015, 2017). Small black dots: earthquakes from the EHB bulletin 1960-2008. (b) Overview of the western Suusamyr basin. Black stars mark the epicentres of the Suusamyr earthquake and two largest aftershocks (Mellors et al. 1997). Black, ticked lines mark the main active fault traces (from our own mapping). The 1992 earthquake ruptured sections in the west (white lines) and east (labelled Fig. 2).

The second rupture site is $25 \mathrm{~km}$ to the west of the M41 site, along the northern range front of the Suusamyr Range. Ghose et al. (1997) report that the ruptures there are split into three segments that stretch for $\sim 3.4 \mathrm{~km}$ across the hillside west of the Dzhalpaksu River (Fig. 1b). These segments are also interpreted to be northfacing reverse ruptures with, from east to west, lengths of $800 \mathrm{~m}$, $1.2 \mathrm{~km}$ and $1 \mathrm{~km}$ and maximum vertical displacement of 1.8, 0.9 and $0.8 \mathrm{~m}$, respectively, although these measurements were taken on a reconnaissance visit, rather than as a detailed survey. Bogachkin et al. (1997) reported that the western ruptures spanned more than $6 \mathrm{~km}$ but did not give sufficient detail on the location or number of rupture segments for us to understand the discrepancy between their value and that of Ghose et al. (1997), as the two figures in Bogachkin et al. (1997) show rupture segments that were also described by Ghose et al. (1997).

Bogachkin et al. (1997) and Ghose et al. (1997) differ on whether the surface ruptures showed a strike-slip component. Bogachkin et al. (1997) reported up to 10-15 cm right-lateral component of 

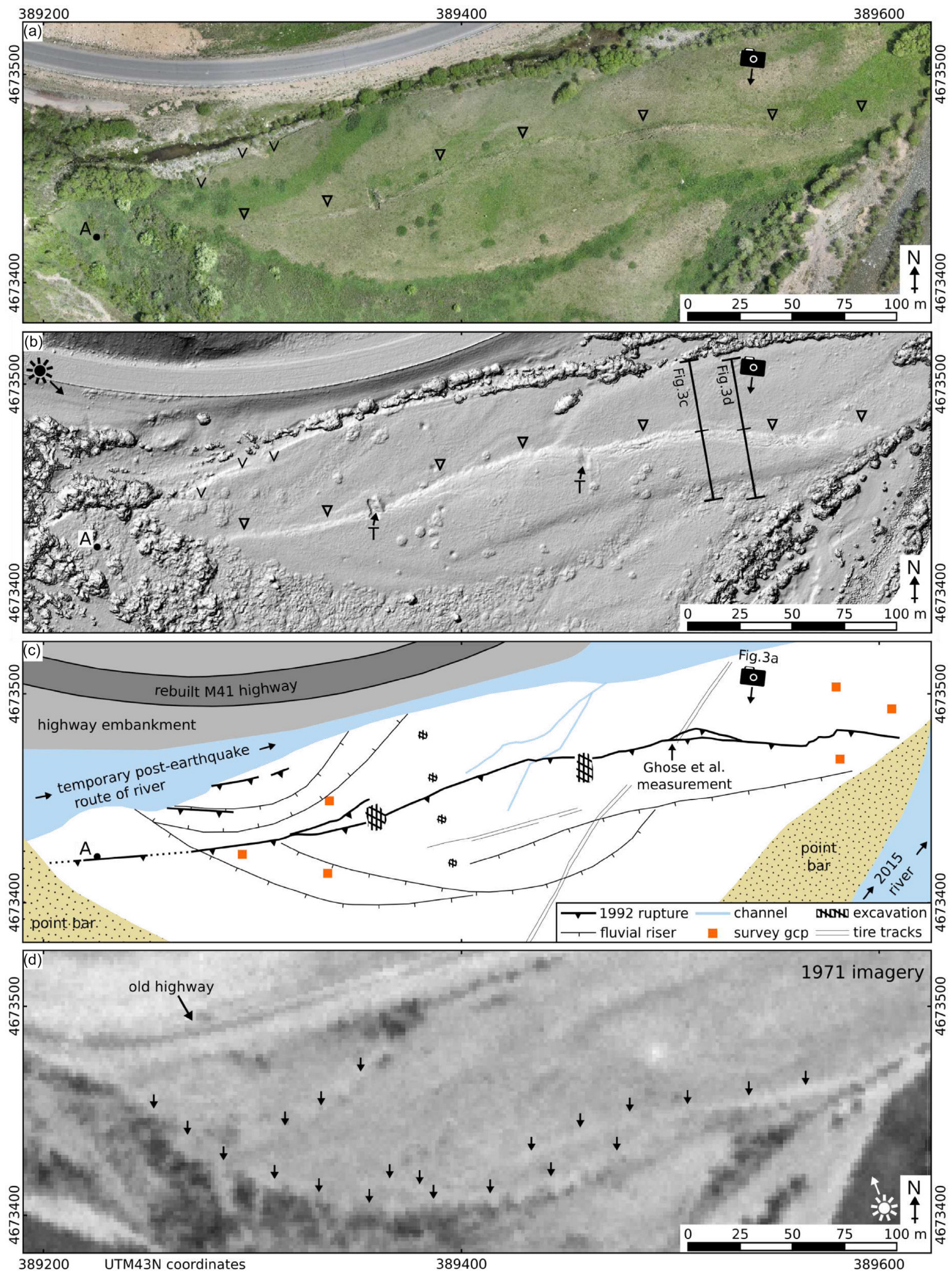

Figure 2. (a) UAV orthophoto showing the eastern 1992 ruptures at the M41 highway. (b) Hillshaded UAV-DEM of the same area. Triangles mark the main scarp, Vs mark minor scarps, and T marks old trench sites. A marks the zero point of Fig. 3(b). (c) Geomorphic map of the area shown in panels (a) and (b). (d) KH-4B CORONA imagery acquired on 1971 September 22 showing the same area before the earthquake. Arrows point to the fluvial risers marked in panel (c). 
slip at the western ruptures and $20-30 \mathrm{~cm}$ at the eastern site, in keeping with the right-lateral component of the seismic mechanism. Ghose et al. (1997) did not find evidence for lateral slip but the heavily broken soil and turf at the eastern site could have masked a small (e.g. 20-30 cm) lateral component, and a $\leq 10-15 \mathrm{~cm}$ lateral displacement could also have been missed on their visit to the western ruptures.

Secondary cracks and fissures were reported in several places along the valley, notably a series of grabens along the crest of the CKR and a series of cracks associated with landslides on the Aramsu Range south and southeast of the primary rupture by the M41 highway. Landslides on the south side of the CKR also broke the highway, large boulders adjacent to the ridge were displaced and overturned by strong acceleration, and numerous other landslides and rockfalls occurred in the region (Ghose et al. 1997).

\section{METHODS}

\subsection{Remote sensing and field methods}

We conducted reconnaissance and preparatory mapping using satellite imagery and DEMs. The imagery included post-earthquake Pléiades optical scenes and pre-earthquake declassified US Key Hole (KH) spy satellite images taken in 1968 and 1971 for the CORONA program, supplemented by sub-5-m resolution images from the archived historical imagery available on GoogleEarth and Nokia Here. The DEMs came from Pléiades imagery, AW3D30 (Takaku et al. 2014) and the Shuttle Radar Topography Mission (SRTM; Farr et al. 2007).

We constructed a high-resolution DEM of the area of interest from three stereo pairs of Pléiades imagery acquired on 2015 September 9 and 21, supplied as $0.5 \mathrm{~m}$ resolution panchromatic and $2 \mathrm{~m}$ resolution four-band multispectral versions. We extracted an elevation pointcloud from the panchromatic imagery using ERDAS Imagine's Leica Photogrammetry Suite (LPS) software. Detailed descriptions of our method can be found in Middleton et al. (2015) and Zhou et al. (2015). Briefly, the method involves identifying a few tens of tie points that the images have in common and using those tie points to refine the rational polynomial function (RPF) model that describes the relationship between image coordinates and ground coordinates. Next, many more common points between the two images are identified using pixel-by-pixel matching with a $9 \times 9$ sized cross-correlation window. The locations of a point in the two images are triangulated with the RPFs of those images in order to determine the 3-D position of that point. We gridded the resulting pointcloud at $2 \mathrm{~m}$ spacing to make a raster DEM. Finally, we used panchromatic images to pansharpen the multispectral images, and used the DEM to orthorectify them before they were used for mapping.

We conducted field surveys in June 2015 and June 2016 to ground-truth our remote mapping, conduct unmanned aerial vehicle (UAV) and differential GPS surveys, excavate trenches and sample for chronological controls. We took aerial photographs from a compact digital camera mounted slightly off-nadir on a UAV. The surveys were conducted using a DJI Phantom 2 quadcopter at a typical flying altitude of 50-110 m, and included some flight paths with convergent viewing directions in order to minimize doming error in the elevation models (James \& Robson 2014). We constructed dense pointclouds and orthophotos from the photographs using the structure-from-motion method with Agisoft's Photoscan Pro software (e.g. Westoby et al. 2012). Ground control point markers were measured in the field using differential GPS and used to scale and orient the point cloud. Offset measurements were made from the dense point cloud.

To determine the history of surface rupturing earthquakes in the Suusamyr valley we excavated two palaeoseismic trenches and logged them in the field. We selected trench locations in small abandoned stream channels to maximise the chance of a continuous supply of fine sediment and we selected locations where the local strike is roughly parallel to the overall strike of the fault. We constructed trench photomosaics using Agisoft Photoscan Pro and used the photomosaics to guide the digitization of our trench logs.

\subsection{Quaternary dating procedure}

We obtained age constraints from sediments within the trenches from radiocarbon $\left({ }^{14} \mathrm{C}\right)$ and infrared stimulated luminescence (IRSL) dating. Note that, in keeping with convention, we have given 2-sigma uncertainties for the radiocarbon dates and 1-sigma uncertainties for the IRSL dates. ${ }^{14} \mathrm{C}$ samples were dated by BetaAnalytic and calibrated using OxCal4.3 (Bronk Ramsey 2009) with the IntCal13 curve (Reimer et al. 2013). We note that, as for all detrital samples, our samples are susceptible to inheritance because the event dated by charcoal ${ }^{14} \mathrm{C}$ dating is the fixation of the carbon in the living source plant rather than the sample's final deposition, which could have been some time later (Blong \& Gillespie 1978; Schiffer 1986).

Luminescence samples were collected from freshly cleaned exposures by hammering $5 \mathrm{~cm}$ diameter steel tubes into the trench wall. When a tube was removed the exposed end was quickly sealed and packed solid. Sample preparation followed the protocols described in Abdrakhmatov et al. (2016). The details of the environmental dose rate determination are given in Appendix A. Coarse grain $\mathrm{K}$ feldspars were analysed using the post-IR IRSL single aliquot regeneration method (Murray \& Wintle 2000; Thomsen et al. 2008; Buylaert et al. 2009). This uses an initial low temperature $\left(50^{\circ} \mathrm{C}\right) \mathrm{IR}$ stimulation followed by a higher temperature $\left(225^{\circ} \mathrm{C}\right)$ stimulation. Slight over-dispersion in the resulting equivalent doses was seen for all samples, that is, there was a spread in equivalent dose $\left(D_{e}\right)$ distributions for the individual aliquots beyond what is expected from individual measurement uncertainties alone (Galbraith et al. 1999). The equivalent dose distributions for all samples are also positively skewed, consistent with some proportion of the grains being incompletely bleached on deposition (e.g. Olley et al. 1998; Arnold et al. 2007). This is manifested in several high outliers in the equivalent dose distributions (Fig. A1). These were removed when outside $1.5 \mathrm{x}$ the interquartile range (following Medialdea et al. 2014), before averaging using the central age model (CAM; Galbraith et al. 1999). The pIRIR 25 ages for samples KGZ15-L02 and KGZ15-L03 had fading rates above 2 per cent ( $g$-values $2.0 \pm$ 0.3 and $2.4 \pm 0.2$ per cent, respectively), so an additional fading correction following Huntley \& Lamothe (2001) was applied to their final ages.

\subsection{Measurement of scarp heights and conversion to slip}

The scarp heights presented in this study were measured using the following method. We took swath profiles with a width of $50 \mathrm{~cm}$ from the dense point cloud of the UAV DEM. Profiles were taken approximately perpendicular to the scarps but with the azimuth manually adjusted where necessary to ensure that profiles followed, rather than cross-cut, landforms. Matching sections on the hanging 
wall and footwall of each profile were marked out manually. Bushes, snow and excavations were either cropped or avoided and profiles were rejected if slope changes along the profile made it challenging to pick correlative sections. We fitted lines of equal slope to the two marked-out sections using a least-squares method and took the offset between the lines as the scarp height. For four exceptional profiles which we discuss in Section 5.1 it was necessary to fit unequal slopes to the two sections. Error bars show the RMS residual between the points and best-fit lines. We found that, for our sites, fitting different slopes to the two sections usually gave results that were within the existing error bars and we rejected profiles where the different methods gave dramatically different scarp heights (with our system, if the two slopes are unequal then the equal-sloped lines from our preferred method will have a worse fit and so the uncertainty will be reflected by bigger error bars). Our measurements are shown in figures within this paper and are tabulated along with their metadata in the Supporting Information.

Converting scarp heights to estimates of slip magnitude also needs some care. Non-horizontal ground surfaces and nonperpendicular angles between a scarp and the normal to the slope both cause scarp height to be unequal to throw (Thompson et al. 2002; Mackenzie \& Elliott 2017). The site of the eastern 1992 ruptures (M41 site) has a slope of almost zero and the Turabulak site has a consistently shallow $\left(4^{\circ}\right)$ slope perpendicular to the scarp, such that scarp height is approximately equal to throw. The slope at the 1992 western ruptures (Dzhalpaksu site) often exceeds $10^{\circ}$ and the aspect varies along strike. Therefore, to rule out geometry effects, we extended Mackenzie \& Elliott (2017)'s method for throw estimation from profiles and added functionality to estimate the magnitude of slip and 68 per cent probability error bars as described in Section 4.

\section{SURFACE RUPTURES FROM THE 1992 EARTHQUAKE}

From satellite imagery verified with fieldwork we have identified $\sim 7.6 \mathrm{~km}$ of scarps which show signs of having ruptured in the 1992 Suusamyr earthquake - a $5.4 \mathrm{~km}$ addition to the $2.2 \mathrm{~km}$ of ruptures mapped by previous publications (Bogachkin et al. 1997; Ghose et al. 1997). The majority - around $6.9 \mathrm{~km}$ - are found within a $12 \mathrm{~km}$ stretch around the Dzhalpaksu and Cholgondysai streams, and a previously mapped $525-600 \mathrm{~m}$ long scarp is located $23 \mathrm{~km}$ east of there, close to the M41 highway (A, B and C in Fig. 1). In this section we review and reassess the location and dimensions of the 1992 ruptures.

\subsection{M41 highway: the eastern ruptures}

The largest-offset ruptures from the 1992 earthquake are developed in a low river terrace between the M41 highway and a bend in the Suusamyr River (A in Figs 1 and 2). The uplift of the southern side of the ruptures during the earthquake dammed the river and caused a short-lived partial diversion of the main river around the northern side of the fault (Ghose et al. 1997; Fig. 2). The scarp is well preserved: cracks and rips in the grass are still obvious in the field (Fig. 3a) and in our point cloud, so we are confident that there has been only minimal site modification since the river adopted its current course shortly after the earthquake. Ghose et al. (1997) interpreted the morphology as a 'fold-scarp' with a gentle southern backlimb and a steeper frontal side. With the aid of declassified 1971 KH-4B imagery (Fig. 2d) we see that the supposed backlimb escarpment predates the earthquake and we therefore interpret it instead as a fluvial riser. The hanging wall is slightly warped: for around half of our topographic profiles the hanging wall section slopes a few degrees more steeply to the north than the footwall (e.g. Fig. 3d) but the impact of this on our offset measurements is small compared to the height of the scarp and is captured within the error bars. In its 200-m long highest section the scarp has a typical height of around $2.7 \mathrm{~m}$ and a maximum height of $3.1 \pm$ $0.1 \mathrm{~m}$ (Fig. 3). The offset tails off quickly to either side, down to $0.5 \mathrm{~m}$ as it approaches the river to the west and $1.4 \pm 0.1 \mathrm{~m}$ to the east where it is truncated by a point bar. Two subsidiary scarps along the bank of the temporary river channel are still clearly visible and have heights up to $0.9 \mathrm{~m}$ (Fig. 2), a third mapped by Ghose et al. (1997) is now overgrown. Ghose et al. (1997) used observations of an offset track oblique to the fault and assumed no lateral slip (which makes this an upper bound estimate) to measure cross-fault convergence and estimate a maximum slip of $4.2 \pm 0.4 \mathrm{~m}$ (location marked in Fig. 2). Their uncertainty value of $\pm 0.4 \mathrm{~m}$ was assigned by allowing a 10 per cent margin of error. Our scarp height measurements agree with theirs used in this estimate. Using our maximum scarp height of $3.1 \pm 0.1 \mathrm{~m}$ and assuming a maximum plausible dip of $60^{\circ}$ [the steepest dip estimate from the seismological studies (Gómez et al. 1997; Mellors et al. 1997)], we find that the maximum slip has a lower bound of $3.6 \pm 0.1 \mathrm{~m}$. We were unable to find any additional markers to measure horizontal displacements.

The most striking characteristic of the eastern rupture is its small length to height ratio. Our elevation models and imagery suggest that the original mapping did not miss any extensions of the rupture. Across the river to the west the ground is only thinly vegetated and the only escarpments visible in satellite imagery or our Pléiades DEM appear to be fluvial and are also visible on pre-1992 CORONA imagery. On the eastern side of the rupture there is a $250 \mathrm{~m}$ wide area in which the river now makes a hairpin bend. The land within the hairpin is seasonally flooded so any scarps may have been quickly eroded but, as shown in Fig. 3(b), the scarp tapers quickly as it approaches the river on either side, suggesting that the scarp naturally ended within the river. Ghose et al. (1997) reported that the scarp created rapids in the river at both its ends and mapped the scarp as crossing the entire width of the river. Assuming that the scarp broke at least half way across the river on each side and at most broke the whole width of the river, the total length of the eastern rupture is therefore 525-600 m.

\subsection{Dzhalpaksu: the western ruptures}

The second set of 1992 ruptures lie $25 \mathrm{~km}$ to the west of those described in Section 4.1 and track across the northern hillside of the Suusamyr Range (B in Figs 1 and 4). They comprise three segments to the west of the Dzhalpaksu River which were identified by Ghose et al. (1997) and Bogachkin et al. (1997), and two newly mapped segments east of the river. We find that the relative locations of the three previously identified segments are as described by Ghose et al. (1997), but the lengths are significantly shorter than the $3.4 \mathrm{~km}$ total length that they estimated. Including the hillside between segments, the previously identified ruptures span $2 \mathrm{~km}$; the ruptures themselves total $1.5 \mathrm{~km}$ in length. Ghose et al. (1997) were unable to conduct a detailed survey of the three segments that they identified; we visited all three in the field and constructed DEMs and orthophotos derived from UAV survey photographs. The western and central segments of the three have lengths of 340 and $550 \mathrm{~m}$, respectively (Fig. 5). They strike $\sim 104^{\circ}$ and overlap in a stepover 


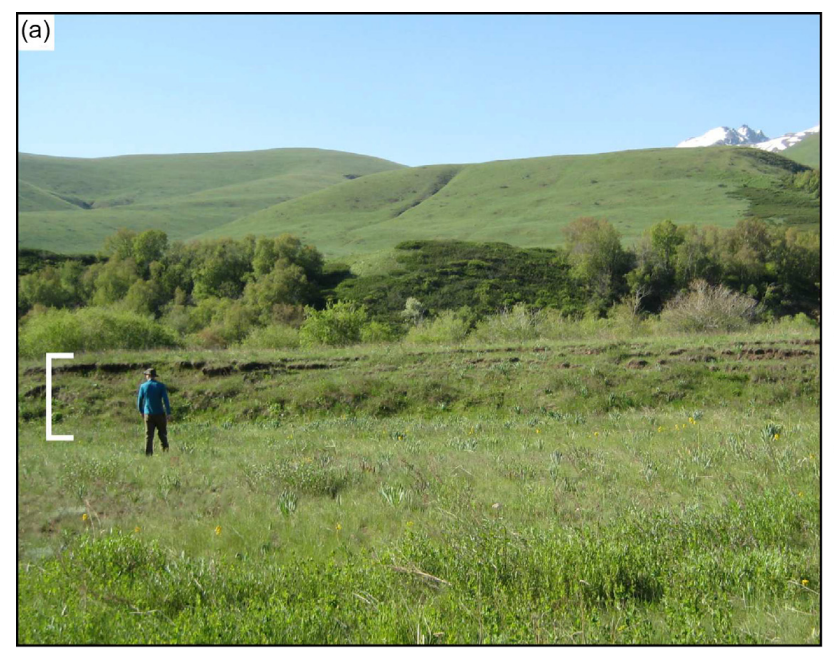

Distance along scarp from A to east on azimuth $080(\mathrm{~m})$
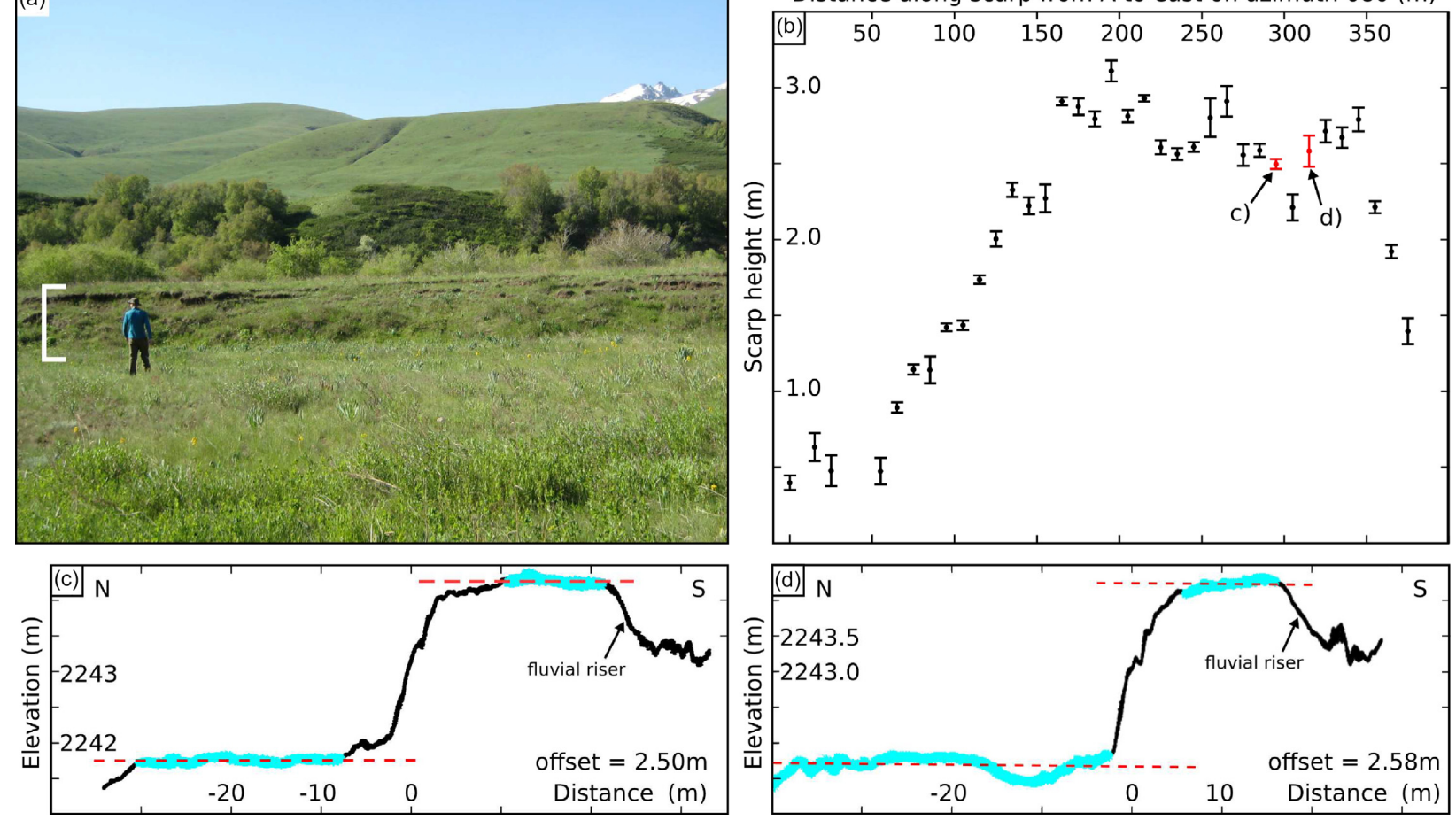

Figure 3. (a) Field photograph of the eastern rupture from 1992, viewpoint marked in Fig. 2. (b) Scarp height distribution. (c and d) Examples of the profiles used to make the throw distribution.

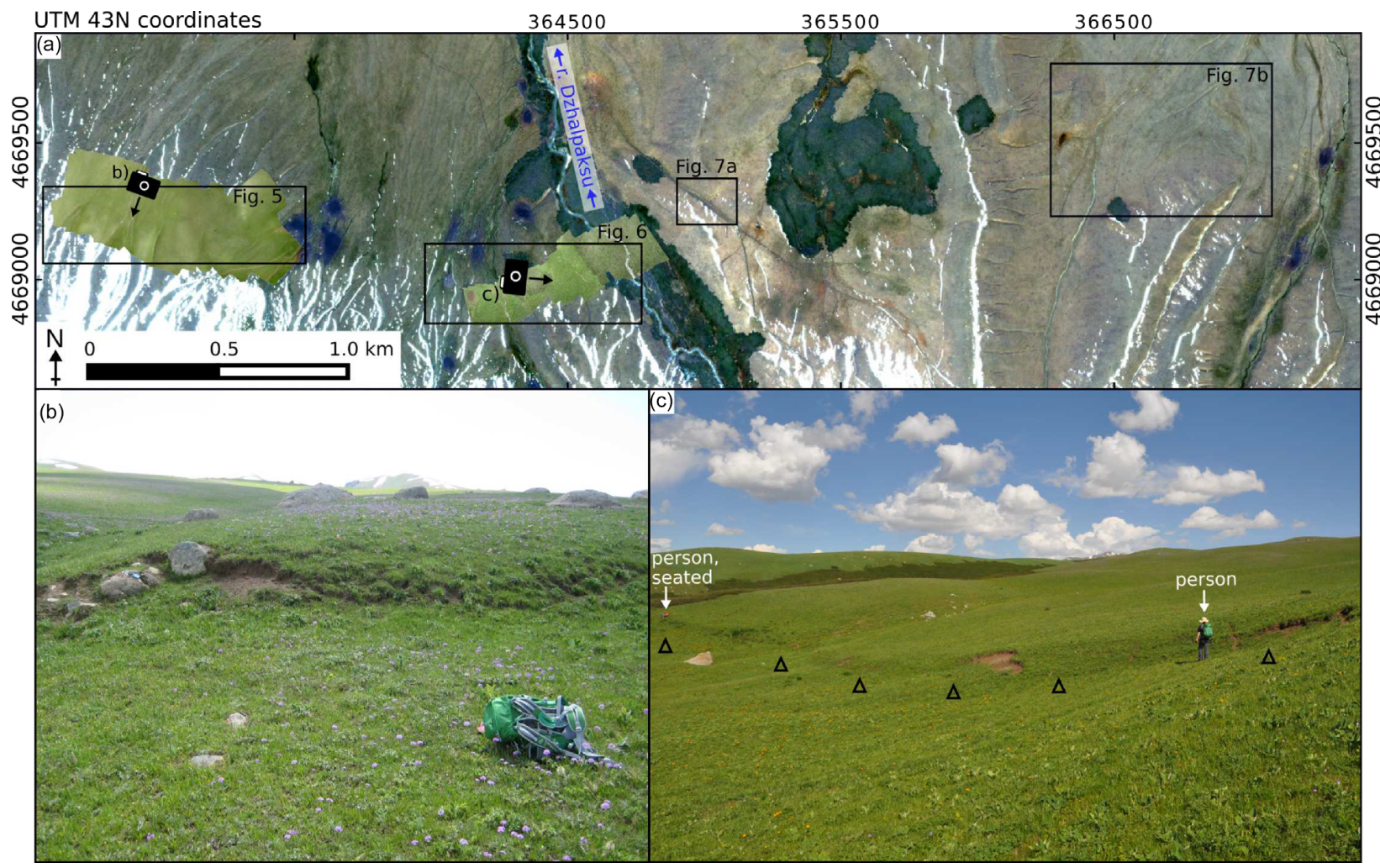

Figure 4. (a) An overview of the 1992 ruptures around the Dzhalpaksu River showing orthophotos from the two UAV surveys. (b) A close-up photograph of the scarp, day rucksack for scale. (c) View along a section of the scarp. 


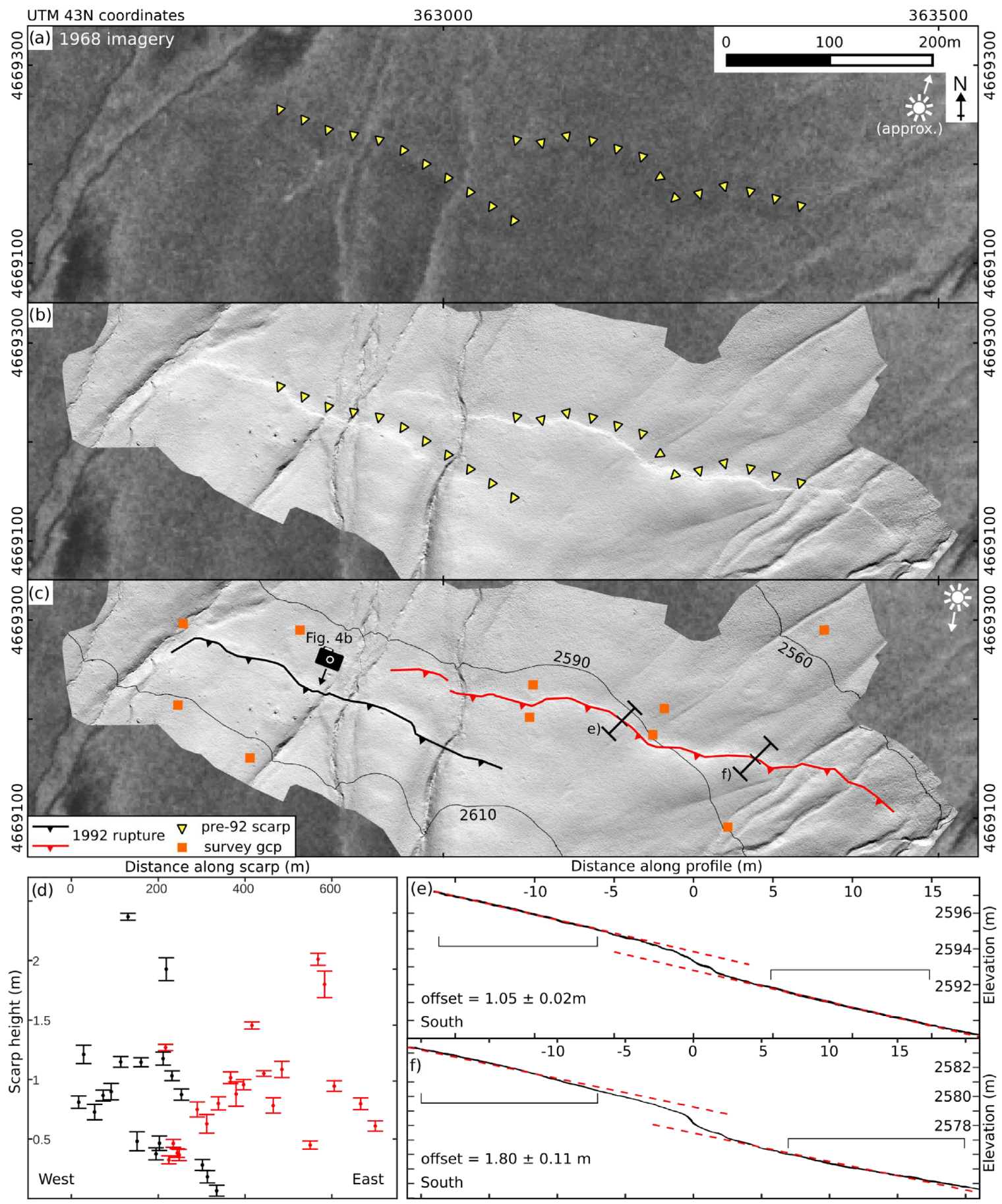

Figure 5. The site of two segments of the 1992 ruptures west of the Dzhalpaksu River (Fig. 4). (a) Pre-earthquake 1968 September 21 KH-4A imagery showing pre-existing scarps marked by yellow triangles. (b) The same area, overlain with a hillshade of our $10 \mathrm{~cm}$ resolution DEM acquired in June 2016. (c) Interpreted version of the hillshaded DEM showing the 1992 ruptures. (d) Height distribution of the two rupture segments shown in panel (c). Distance along scarp is a straight line distance along azimuth $104^{\circ}$. (e) A typical example of the profiles used to measure scarp height. The best-fit lines are shown in dashed red and the sections of the profile that they were fitted two are marked. (f) Example of a profile with higher uncertainty. The hanging wall section (south) has non-uniform slope and is $3^{\circ}$ steeper than the footwall section.

zone, with the central segment $40-70 \mathrm{~m}$ downslope of the other. The third segment is located $600 \mathrm{~m}$ to the east and has an overall strike of $\sim 68^{\circ}$ (Figs 1 and 6). It extends for $600 \mathrm{~m}$ to the west of the Dzhalpaksu River before being obscured by vegetation as it approaches the river itself (Fig. 6).

Although the scarps are fresh and reports from the time confirm that they broke in the 1992 earthquake, $1968 \mathrm{KH}-4 \mathrm{~A}$ imagery shows scarps in the same location as the west and central segments which even match the bends of the 1992 ruptures (Figs 5a and b), showing that the 1992 earthquake re-ruptured a pre-existing scarp. Our offset measurements in Fig. 5 are therefore compound scarp offsets rather than single-event offsets. No pre-existing scarp is visible for the third segment closest to the Dzhalpaksu River and the scarps visible on the KH-4A imagery do not extend beyond the extent of the 


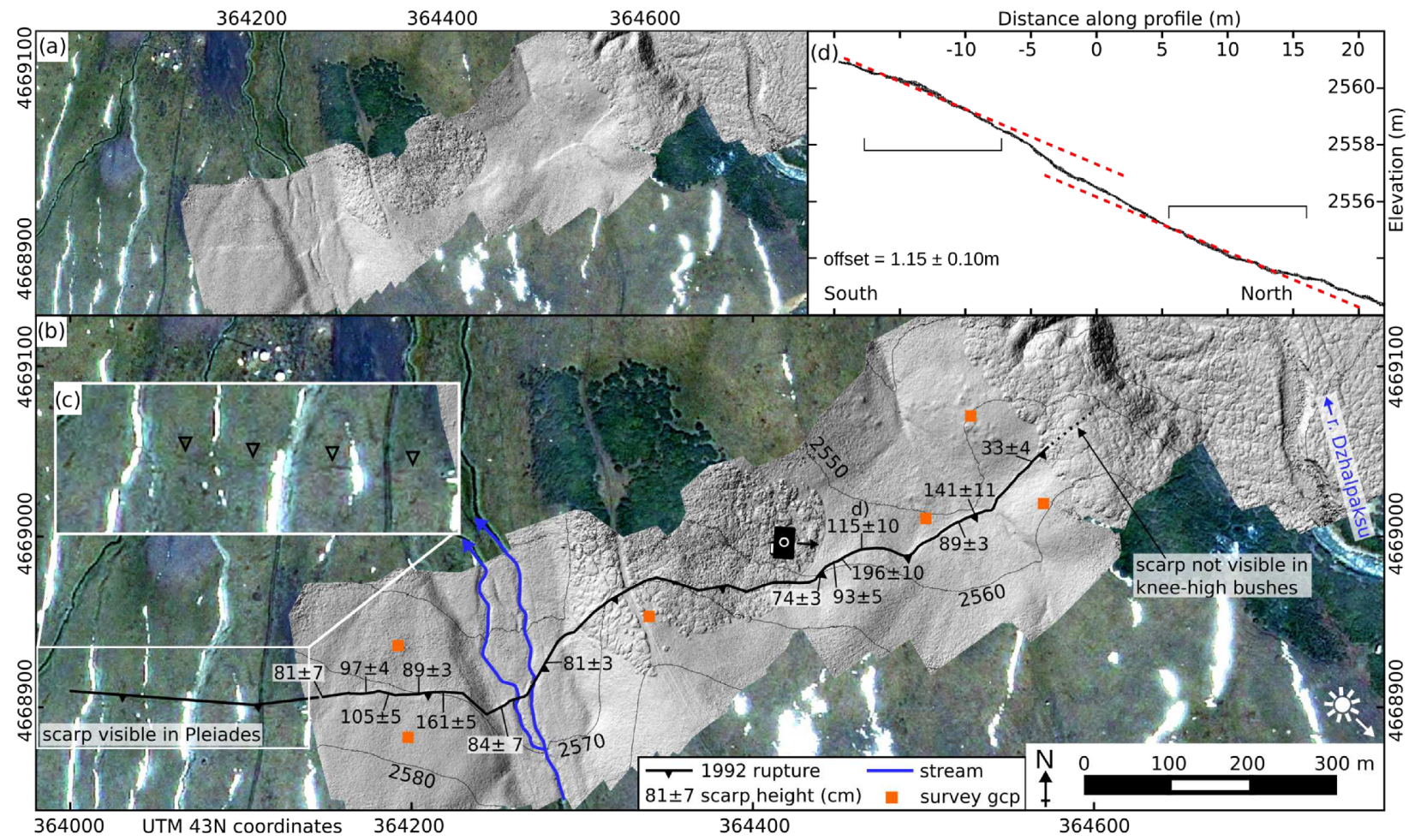

Figure 6. The easternmost of the three 1992 surface rupture segments west of the Dzhalpaksu River, described by Ghose et al. (1997). (a) Hillshaded UAV DEM overlain on Pléiades imagery. (b) Interpretation. (c) Close-up of the Pléiades imagery. (d) A typical topographic profile. The best-fit lines are shown in dashed red and the sections of the profile that they were fitted to are marked.

fresh 1992 rupture. Significantly, this suggests that the prehistoric earthquake or earthquakes also only ruptured short segments.

Figs 5(d) and 6(b) show scarp height distributions for the three segments which had been identified previously. The three have similar heights; exceptional profiles show offsets of $2 \mathrm{~m}$ or more but more typically the scarp height is around $0.7-1.2 \mathrm{~m}$. At the stepover between the western and central segments the two scarps taper so that total offset remains roughly the same along strike until it dies out at the ends of the ruptures. To convert our scarp height measurements to slip estimates we have used an extended version of the profile method of Mackenzie \& Elliott (2017), which takes into account fault dip, slope aspect, slope angle, the proportion of lateral slip and their uncertainties. Using a uniform probability density function of $15^{\circ}-45^{\circ}$ for dip, lateral slip of \pm 10 per cent and appropriate slope and aspect for each profile, our profiles typically have a maximum-likelihood slip of $0.9-1.5 \mathrm{~m}$ with a large upper error bar due to the uncertainty in near-surface fault dip. The distribution of calculated slip along strike is not much changed in shape from the scarp height distribution, showing that the distribution in Fig. 5(d) reflects real distribution of slip reaching the surface and is not an illusion caused by the effects of geometry. We did not observe any lateral offsets here but note that extremely few good markers cross the scarps which would show lateral offsets, and some small-scale evidence could have been lost due to erosion.

Although Ghose et al. (1997) and Bogachkin et al. (1997) did not map any ruptures on the hillside to the east of the Dzhalpaksu River, we have mapped two fresh segments that we interpret from their morphology to have ruptured in 1992. The first lies $400 \mathrm{~m}$ alongstrike to the east of the mapped segment, is $130 \mathrm{~m}$ long and can be seen in Pléiades imagery (Figs 4 and 7a). The second rupture is $530 \mathrm{~m}$ in length and situated $1400 \mathrm{~m}$ east from the first on an azimuth of $082^{\circ}$ (Figs $7 \mathrm{~b}$ and c). Although we were unable to visit either of the newly mapped segments in the field, the $530 \mathrm{~m}$ segment has similar or slightly less shadowing in the imagery than the alreadymapped scarps and the shorter segment does have less shadowing, suggesting that they have smaller heights than the already-mapped scarps. A GoogleEarth image with snow cover (Fig. 7b) shows the scarps casting a shadow when illuminated from the south-southeast, meaning that, like the previously mapped ruptures, these scarps are north-facing. Their age is unknown but they are unvegetated and have thin parallel, black strands that we interpret as open fissures, both qualities that match the 1992 scarps rather than the prehistoric scarps we show in Section 5.

\subsection{Cholgondysai}

A 4-km long fault scarp begins $6 \mathrm{~km}$ to the west of the western end of the Dzhalpaksu ruptures, along-strike (C in Figs 1, 8 and 9). In its eastern half there is a significant change in slope and roughness across the scarp from steeper, rougher topography in the south to shallower, smoother topography downhill on the northern side. The scarp here has occasional fissures (Fig. 8a). After a $180-\mathrm{m}$ wide stepover southwards the fault continues and crosses the Cholgondysai stream. In this section the fault cuts across topography with a dip of $>70^{\circ} \mathrm{S}$ (as estimated in the field, Fig. 9b) and there is a $\sim 1 \mathrm{~km}$ segment with abundant en-echelon open fissures indicating a right-lateral slip component (Fig. 8b). The right-lateral component is also apparent in the larger-scale morphology - the offset is predominantly south-up but the vertical offsets are larger on westfacing ridge slopes than on east-facing slopes and on one east-facing slope the scarp appears to be north-up (Fig. 8a). We conclude that the fault here is a right-lateral oblique thrust. 


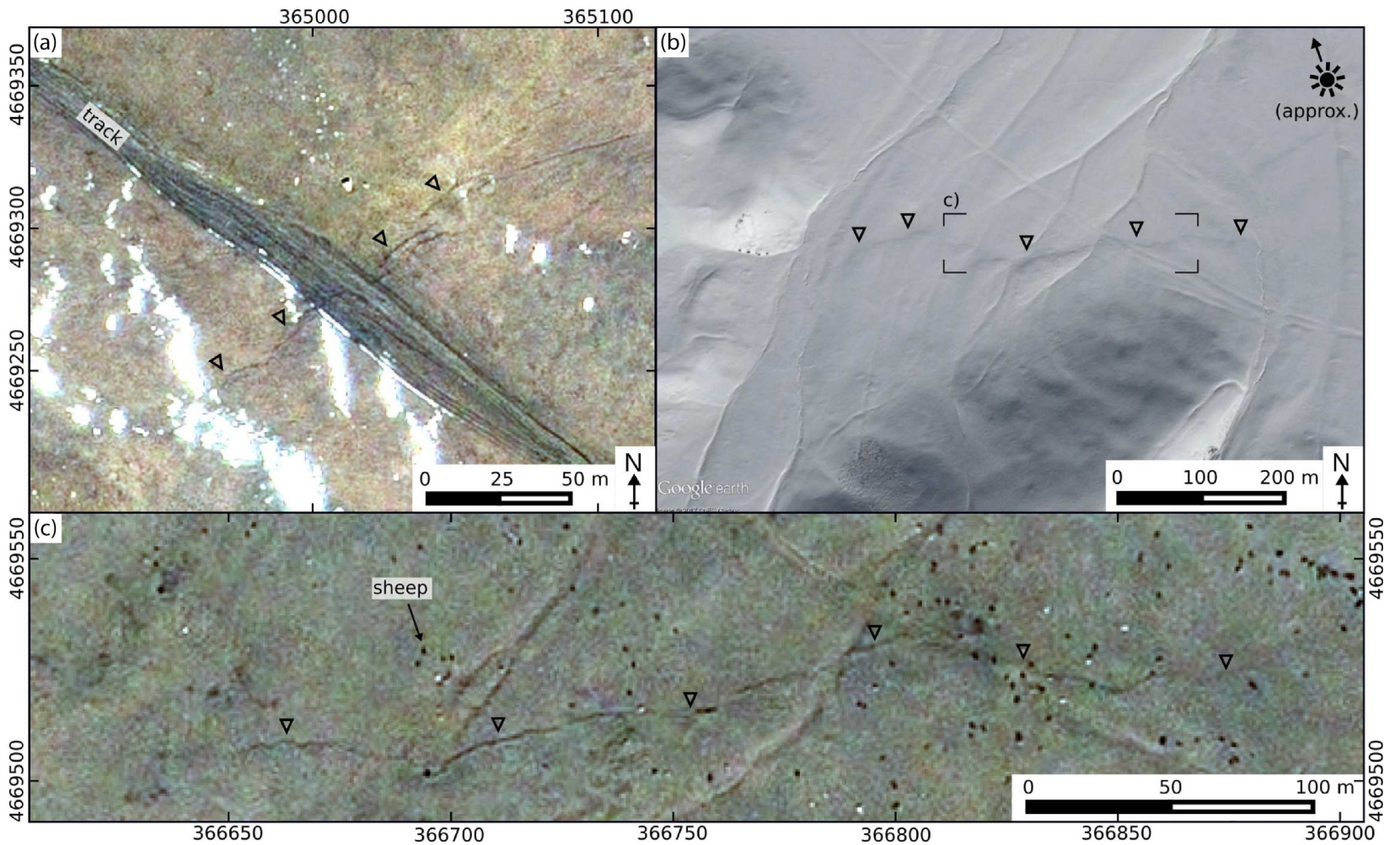

Figure 7. Newly identified surface ruptures, locations shown in Fig. 4. (a) Pléiades imagery of a small scarp east of the Dzhalpaksu River. Note that the scarp is fresh enough for parallel strands of fissures to be visible. (b) Snow-covered 2016 November 19 scene showing the shadow of another scarp. Imagery from GoogleEarth, copyright CNES/Airbus. (c) Pléiades imagery showing the same scarp cross-cutting small channels as shown in panel (b).

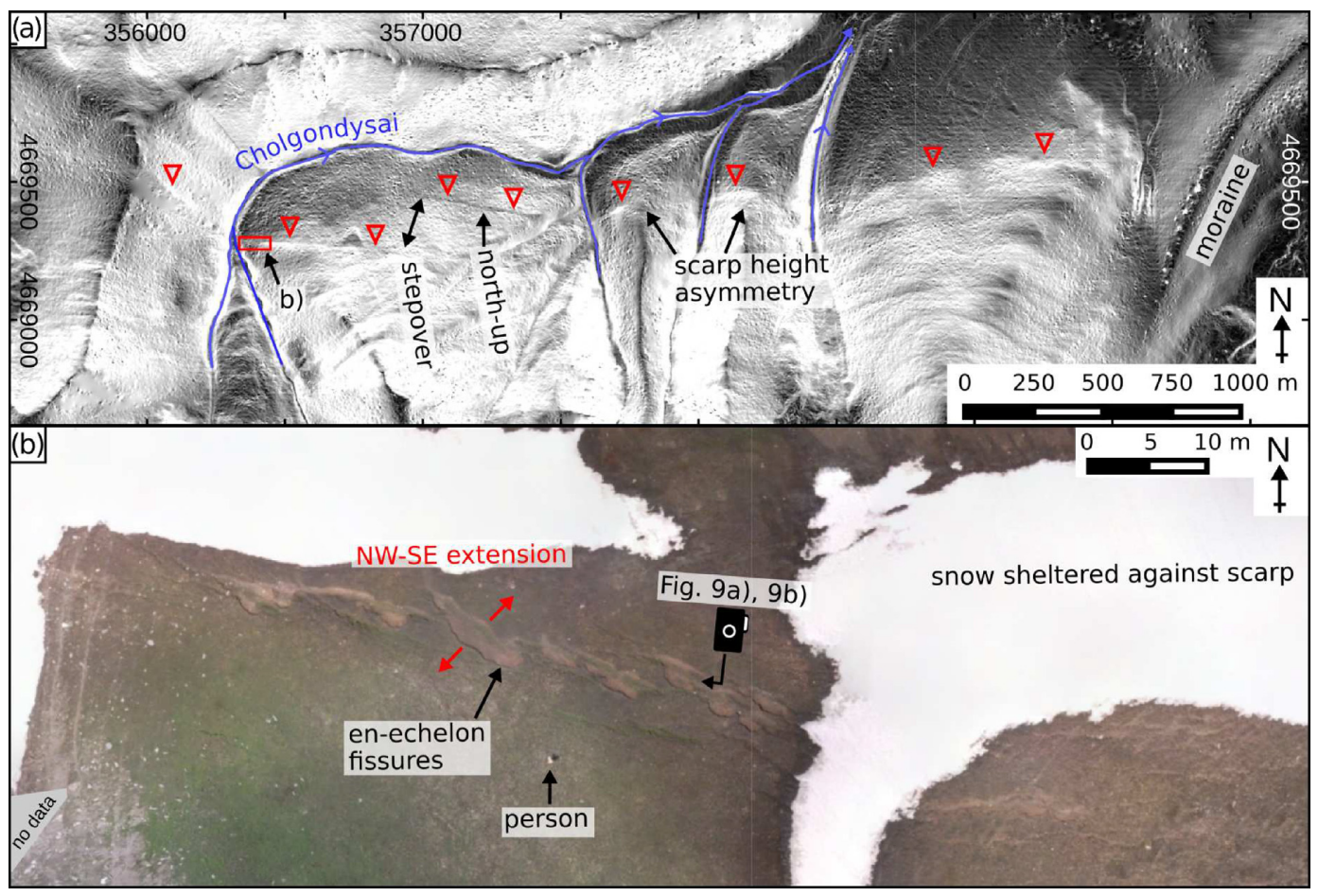

Figure 8. The Cholgondysai fault segment. (a) Slope map of the Pléiades DEM. The scarp is marked by red triangles. (b) UAV orthophoto of the fresh en-echelon fissures on the scarp close to the Cholgondysai stream. Location shown in panel (a). 


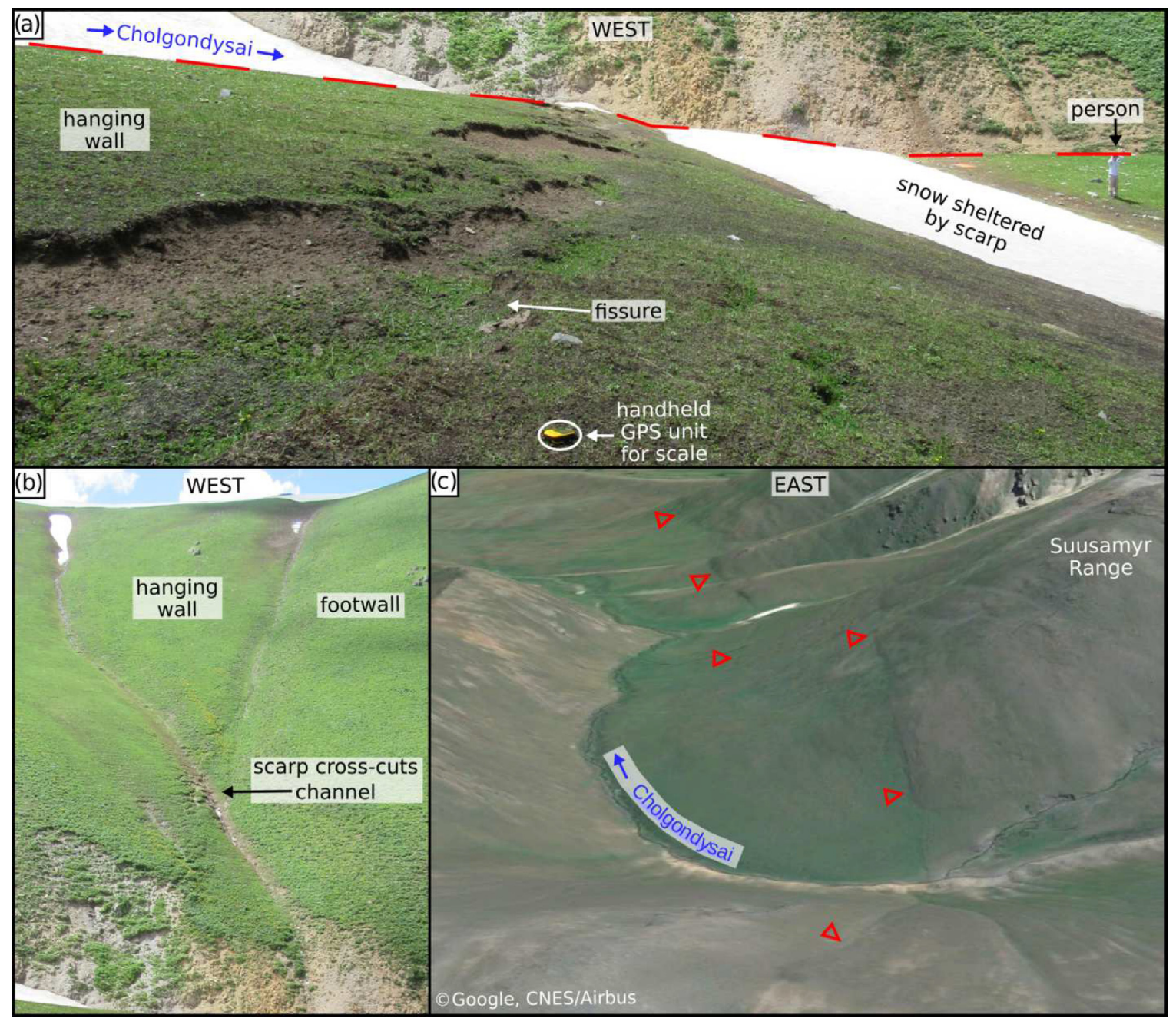

Figure 9. ( $a$ and b) Field photos of the Cholgondysai fault segment showing fresh fissures and the scarp crossing up the hillside steeply. (c) GoogleEarth perspective view looking in the opposite direction along the fault. Our field site is in the foreground. Image acquisition date 2013 August 16.

The entire length of the $4 \mathrm{~km}$ scarp is visible on pre-1992 CORONA imagery and the changes of slope and roughness across it suggest that it has hosted multiple earthquakes. In June 2016 elongate patches of snow were present, sheltered against the northfacing scarp which has a smoothly curved cross-section and a height of 3-8 m. As can be seen in Fig. 9(a), the fissures in the soil on the scarp crest have some young vegetation within them but are generally still sharp-edged and unvegetated, similar to the fissures at the confirmed 1992 scarps (Section 4). There have been no other earthquakes greater than magnitude six in this region in the past century which could have formed the fissures so it is probable that the fissures do date from 1992 reactivation of this compound scarp. At least a $1 \mathrm{~km}$ stretch has abundant fresh fissures and the occasional fissures on the eastern $3 \mathrm{~km}$ of the scarp suggest that it too may have hosted some small displacements in 1992. We have found no evidence of scarps crossing the moraine and hillside between this Cholgondysai fault section and the Dzhalpaksu sections.

\section{PREHISTORIC RUPTURES}

We have already shown two sections of the 1992 earthquake ruptures that reactivated pre-existing scarps. In this section we will describe prehistoric ruptures that we have identified within the epicentral area but were not reactivated in 1992. Both scarps are situated alongside northern edges of anticlines that run through the valley and are within the $25 \mathrm{~km}$ gap between the eastern and western ruptures.

\subsection{Chet-Korumdy Ridge}

The CKR was the site of some of the most intense shaking and significant secondary effects during the 1992 earthquake (Section 2; Ghose et al. 1997). The ridge is approximately $10 \mathrm{~km}$ long and reaches up to $300 \mathrm{~m}$ above the Suusamyr River (Fig. 10). Outcrops in landslide scars on the southern flank of the CKR expose beds of poorly consolidated sediments ranging from coarse sand to $10-\mathrm{cm}$ long cobbles. Although these beds are to the south of the ridge crest, they dip to the northwest (strike $240^{\circ}$ ) at $25^{\circ}-40^{\circ}$, indicating that they are in the northern limb of an anticline and that the Suusamyr River has cut through the core of the fold. Our interpretation of the ridge as a fragment of the northern limb of a fold leads to the conclusion that the grabens that opened along the crest of the ridge in 1992 are most probably related to gravitational collapse during shaking rather than being bending moment faults from fold-growth, which we would expect to find at the fold axis. 


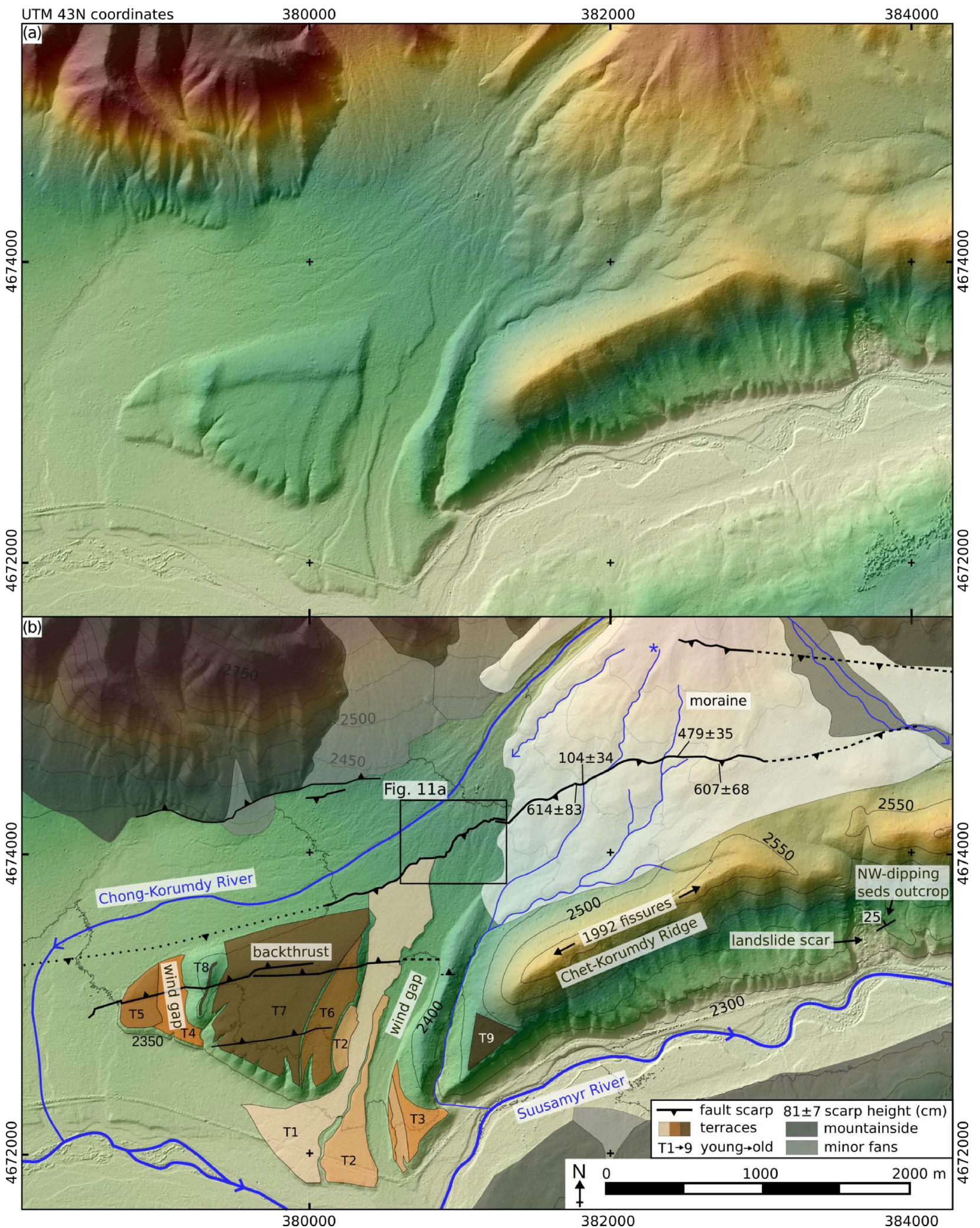

Figure 10. (a) Hillshaded Pléiades DEM for the western end of the CKR (location shown in Fig. 1). (b) Our interpretation of that area. See the text for details.

A moraine from the Talas Range to the north has been emplaced against the western end of the ridge (Fig. 10). The edge of the moraine is truncated on its western side by an alluvial surface belonging to the Chong-Korumdy River, but since incising into the moraine the river has been diverted to the west leaving a wind gap through the CKR (Chediya et al. 1997; Korjenkov et al. 1999) and a suite of low alluvial terraces. A short south-facing scarp cuts the terraces and part of the lowest fan surface, it has greater offset 
where it crosses the older surfaces, showing that its activity has been ongoing through the period of formation of the different surfaces (Fig. 10). We interpret it as a backthrust as the fault trace V's northward in lower topography.

A prominent north-facing scarp runs along the northern edge of the CKR (Fig. 10). In the moraine north of the CKR the scarp is manifested by change in drainage - one prominent stream (marked by a star in Fig. 10) is diverted along the fault and the scarp forms a topographic low perpendicular to the drainage direction. There are few sites suitable for offset measurements in the moraine and for the sites we did select it was necessary to fit regression lines with unequal slopes to the two sides of the profiles so we are cautious about detailed interpretation of the results. However we find vertical displacements of 4.4-7 $\mathrm{m}$ in the moraine surface and for a stream channel we find 0-1.3 m vertical displacement (Fig. 10). After it passes onto the alluvial surface west of the moraine the scarp offsets numerous small, anastomosing north-south channels. Its height is typically $2-3 \mathrm{~m}$ in the eastern part of this section (Fig. 11) but after a left-stepping jog of $150 \mathrm{~m}$ the height decreases to $<1 \mathrm{~m}$. After $\sim 1.3 \mathrm{~km}$ across the fan, the scarp becomes difficult to map further westwards, if it is present at all, due to erosion by scarpparallel channels. The height difference between the scarp in the moraine and the alluvial fan shows that the scarp ruptured in multiple prehistoric earthquakes, with the moraine showing the offsets from events that predate the fan. We can also infer that the fault hosted surface-rupturing earthquakes prior to the diversion of the Chong-Korumdy River and that folding and faulting have occurred contemporaneously.

In the field the scarp is smooth and without visible fissures in the hanging wall (Fig. 11e). To assess the recent activity history of the scarp we dug a trench across it at $42.2104^{\circ} \mathrm{N}, 073.5589^{\circ} \mathrm{E}$ on an azimuth of $334^{\circ}$ (Figs 11 and 12). This is at a point where one of the abandoned small channels crosses the scarp and the scarp height is a relatively low $1.1 \mathrm{~m}$. The full trench log and unit descriptions are given in Figs 12 and 13 and Table 1. The northern side of the trench (footwall) exposed a sequence of sub-horizontal clays and sands down to a depth of $1.8 \mathrm{~m}$, where it reached a densely packed conglomerate (unit 90). We interpret the conglomerate as the main fluvial/alluvial deposit which forms this surface, and the sand and clay to be ponded sediments dammed by the scarp. The hanging wall is made up of a hard boulder conglomerate and a silty clay with gravel clasts, overlain by approximately $50 \mathrm{~cm}$ of poorly sorted soil. The hanging wall units are massive, with very different macrostructure to that of the footwall deposits, so we interpret all of the hanging wall units as being sub-units of unit 90 (the conglomerate), rather than being the result of over-topping of the scarp. In the central part of the trench, below the topographic scarp, the layered clay and sands have been offset and rotated by several strands of reverse faults, and show many plastic deformation structures (Fig. 13). Clasts from the unconsolidated sand and gravel units are smeared out along the fault zone and in parts are aligned with it (unit 120). A thin sand layer (unit 20) caps the fault zone and has not been offset. Above it is poorly sorted soil which we interpret to be sourced from post-earthquake sediment influx, reworking of the unconsolidated fault zone material and erosion of the hanging wall.

We interpret the trench as showing evidence for at least two earthquakes. The first offset the gravel conglomerate (unit 90 and sub-units) and formed an uphill facing scarp. The layers of ponded clay and sand that we now see in the footwall (units 30-80) built up against this scarp and were then faulted in a second earthquake.
Units 10 and 20 postdate the earthquakes; there is no displacement of these units and no disturbance at ground level.

Radiocarbon dates and ISRL ages from samples collected in the trench show increasing age with depth as expected (Fig. 12). Full details of the results are listed in Tables 2 and 3. Sample KGZ15-C02 was collected from unit 20, which postdates the most recent event, and gave an age of 3166-3347 cal yr BP (full $2 \sigma$ range). IRSL samples KGZ15-L01, KGZ15-L02 and KGZ15-L03 were taken from unit 40 , which has been cut by a strand of the fault to give an apparent double thickness layer in the fault zone (see squares C4 and C5 in Fig. 12), this is among the youngest layers to predate the most recent earthquake. The pIRIR 225 samples returned dates of $3.0 \pm$ $0.1,3.0 \pm 0.2$ and $3.5 \pm 0.2 \mathrm{ka}$ (Table 3). The pre-earthquake IRSL ages and the radiocarbon date of sample KGZ15-C02 are indistinguishable, given their uncertainties. Our radiocarbon samples from the oldest ponded sediments deeper in the trench give us a minimum estimate on the date of the penultimate earthquake, subject to the same inheritance caveat. The deepest sample taken from within unit 80 just above the boulder conglomerate gave an age of 7866-8001 cal yr BP and the next, $20 \mathrm{~cm}$ higher, gave 5935-6249 cal yr BP.

In summary, the CKR scarp has ruptured in multiple events; we identify two surface-rupturing events in a trench where the scarp crosses an abandoned fluvial surface. The first is likely to predate $\sim 8 \mathrm{ka}$ and the second is at $\sim 3 \mathrm{ka}$ which, given recurrence rates in the Tien Shan can be several thousand years (e.g. Abdrakhmatov et al. 2016; Deev et al. 2016; Landgraf et al. 2016; Grützner et al. 2017; Patyniak et al. 2017) and we have no reason to think that this fault is exceptionally fast, might have been one of the most recent events in the basin. We do not observe any signs of coseismic or post-seismic displacement from the 1992 earthquake.

\subsection{Turabulak}

Further west, another scarp which did not rupture in 1992 is evident at Turabulak. The scarp is situated approximately $2.2 \mathrm{~km}$ west of the CKR, where a fan deposited by two minor tributaries leaving the Talas Range is interrupted by two small anticlines that warp the fan surface. The eastern anticline is the more prominent of the two, with $50 \mathrm{~m}$ of relief and $1.5 \mathrm{~km}$ length. Southward-flowing drainage is now diverted eastwards around the anticline, with the drainage channel preserved as a wind gap in the fold crest (Fig. 14a). The crest of the smaller, western fold is $230 \mathrm{~m}$ downslope of the eastern fold and is dissected by two active channels and four wind gaps. We have named this site Turabulak, after the name that Soviet-era topographic maps give the western of the two tributaries that flow into the fan.

As at the CKR site (Section 5.1), an uphill-facing, south-up scarp runs across the fan $400 \mathrm{~m}$ north of the western fold. The scarp is faintly visible on Pléiades and GoogleEarth imagery and can be traced for $1.2 \mathrm{~km}$ before it becomes too faint to follow (Fig. 14a). It is not visible across the higher, older surface just to the east. In the field the scarp is identifiable by its small elevation change (typically $15-35 \mathrm{~cm}$ on our UAV DEM, and up to $62 \mathrm{~cm}$ ) and a subtle change in surface lithology: cobbles protrude through the hanging wall grass whereas the footwall hosts slightly greener, thicker grass growing in cobble-free soil (Fig. 14). Topographic profiles through our UAV DEM show that scarp infilling and a rounded hanging wall corner have resulted in a 4-5-m wide subhorizontal scarp area between the two sides of offset, planar, $\sim 4^{\circ}$ sloping alluvial fan (e.g. Figs 14 e and f). 

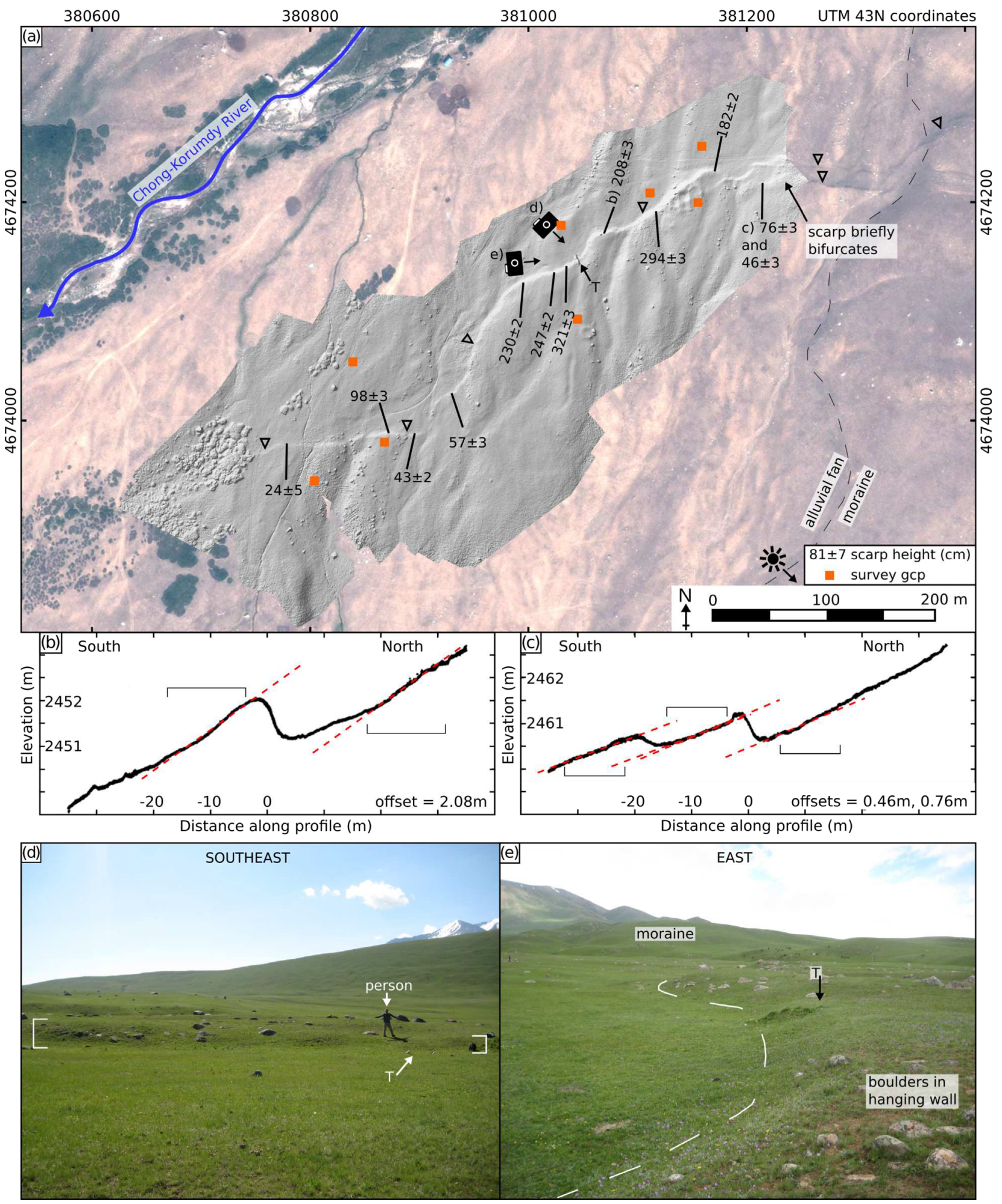

Figure 11. (a) Hillshaded DEM of the uphill-facing scarp around our 2015 trench (T), annotated with scarp heights. (b and c) Topographic profiles. (d and e) Field photographs of the scarp, note that the trench is at a low point in a former channel and that elsewhere boulders are exposed in the hanging wall but buried in the footwall.

We excavated a small trench across the scarp at $42.2029^{\circ} \mathrm{N}$, $073.4766^{\circ} \mathrm{E}$ at a point where the footwall has slightly denser vegetation than average and which is recognizable from the aerial imagery shown in Figs 14(b) and (c) as a minor abandoned channel. For the purposes of our trench log we defined the ground surface at the trench as horizontal. Our trench revealed an alluvial gravel unit made up of well-rounded, $\sim 10$-cm sized, predominantly granite cobbles in a matrix of coarse sand which contained a small fraction of mud. In the hanging wall (south) the gravel reaches the surface with some thin soil covering, in the footwall the top of the gravel layer 


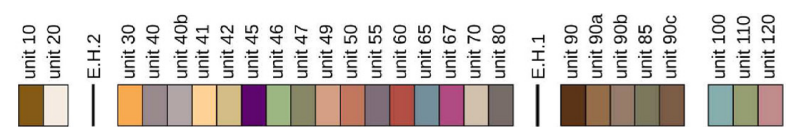
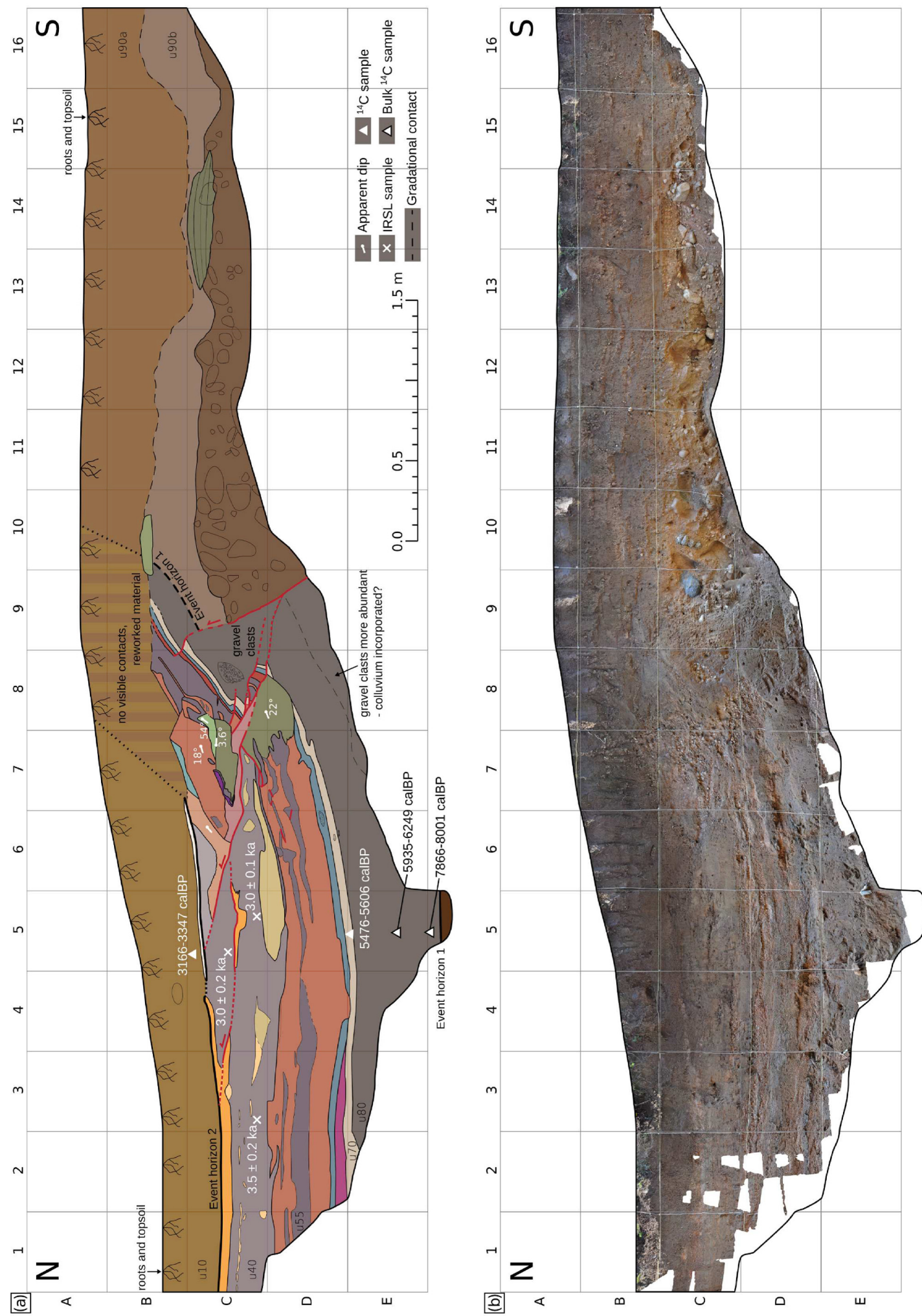

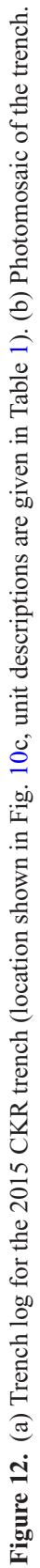




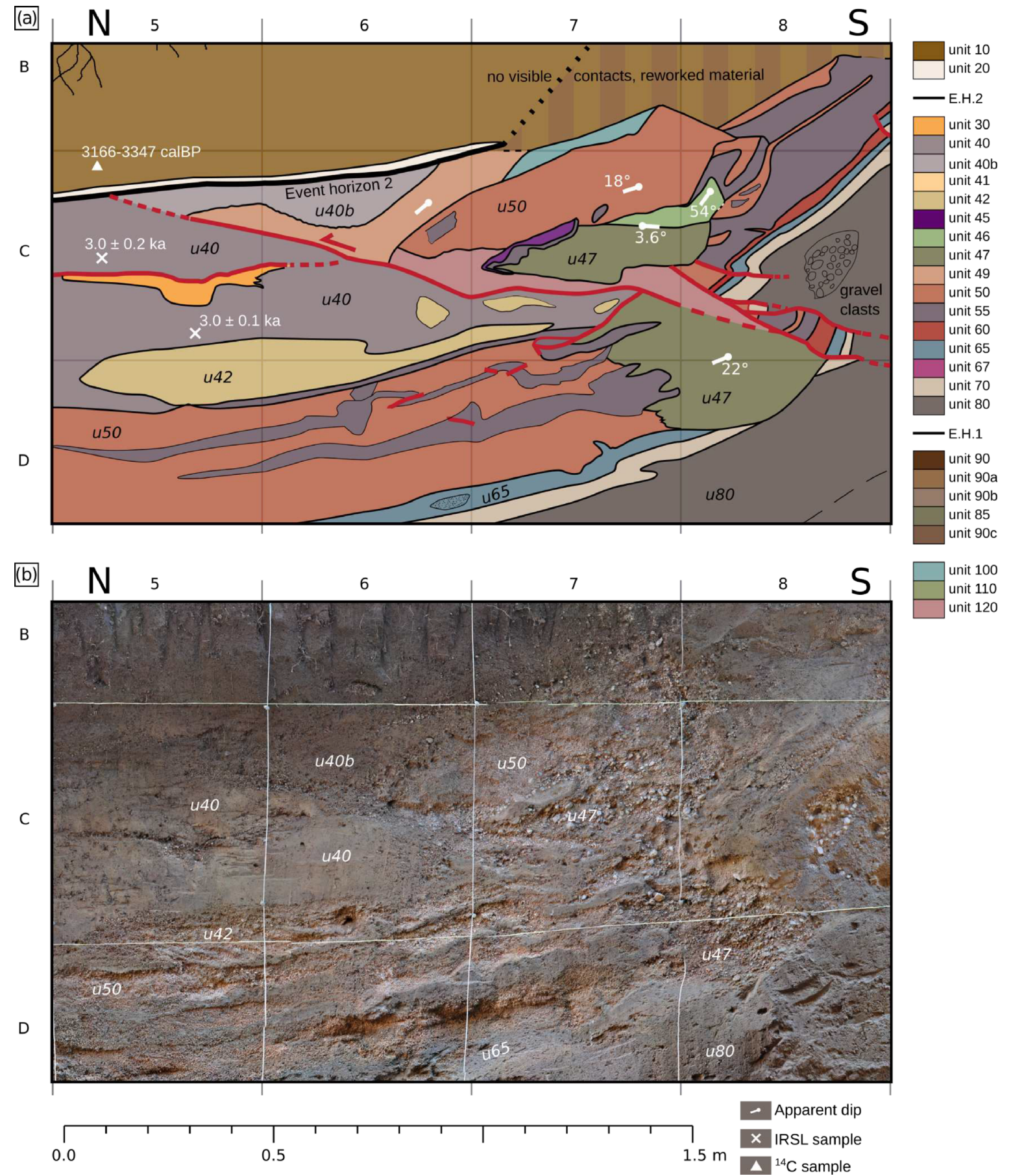

Figure 13. Close-up view of the fault zone from Fig. 12.

is offset $45-55 \mathrm{~cm}$ vertically downwards and the scarp is infilled by uniform sandy soil. The $10 \mathrm{~cm}$ range in our offset measurement is a consequence of the uncertainty in defining the top of the gravel layer in the hanging wall.

We interpret the trench as showing evidence for a single earthquake that offset the gravel layer, forming the scarp which has since been partially infilled by the sandy soil. The fault is not prominent in the trench gravel but we have tentatively marked it along a convex surface across which there was a contrast in cohesion and which was visible on both walls of the trench (Fig. 14), its lower section has an apparent dip of $27^{\circ}$, while the upper portion is sub-horizontal and may be the result of collapse of the hanging wall wedge. Taking a fault dip of $30^{\circ}$, and assuming there is no lateral component of slip, the $45-55 \mathrm{~cm}$ vertical horizontal offset corresponds to $90-110 \mathrm{~cm}$ of slip. Two bulk radiocarbon samples from the base of the soil sediment which postdates the earthquake gave dates of $\sim 4400-4960$ BP (Table 2), so it is likely that the earthquake predates $4.4-4.9 \mathrm{ka}$, but we cannot discount that it is younger than the radiocarbon ages due to inheritance in the radiocarbon. The difference between the two dates can be attributed to inheritance and to the deposition of the soil taking some time. 
Table 1. Descriptions of the sedimentary units identified in the CKR trench (see Fig. 12).

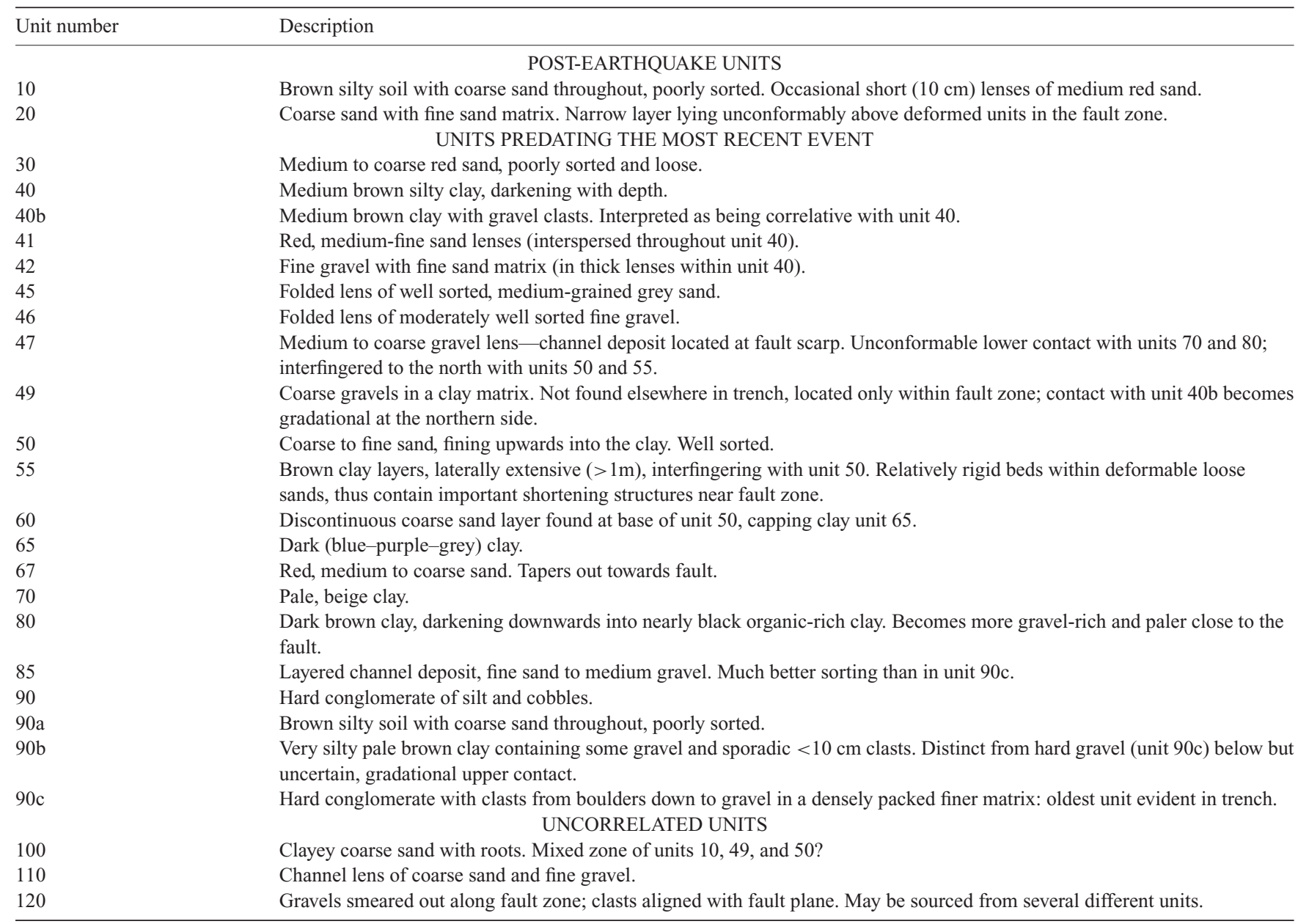

Table 2. ${ }^{14} \mathrm{C}$ dating results. Zero BP (before present) is defined as $1950 \mathrm{AD}$. Tbk: Turabulak trench. CKR: Chet-Korumdy-Ridge trench.

\begin{tabular}{|c|c|c|c|c|c|c|c|c|}
\hline Sample & Location & $\begin{array}{l}\text { Longitude } \\
\quad\left({ }^{\circ} \mathrm{E}\right)\end{array}$ & $\begin{array}{l}\text { Latitude } \\
\left({ }^{\circ} \mathrm{N}\right)\end{array}$ & $\begin{array}{l}\text { Elevation } \\
\quad(\mathrm{m})\end{array}$ & $\begin{array}{l}\text { Depth } \\
(\mathrm{cm})\end{array}$ & Description & $\begin{array}{c}\text { Conventional } \\
{ }^{14} \mathrm{C} \text { Age } \\
\text { (yr BP) }\end{array}$ & $\begin{array}{c}\text { Calibrated date range (95.4 per cent) } \\
\text { (cal yr BP) }\end{array}$ \\
\hline SUU16C05 & Tbk & 073.4766 & 42.2029 & 2422 & 45 & bulk, B layer soil & $4300 \pm 30$ & $\begin{array}{l}\text { 4961-4925( } 9.4 \text { per cent }) \\
4918-4901(2.2 \text { per cent }) \\
4893-4830(83.8 \text { per cent })\end{array}$ \\
\hline SUU16C06 & Tbk & 073.4766 & 42.2029 & 2422 & 60 & bulk, B layer soil & $4010 \pm 30$ & $\begin{array}{l}4567-4561(0.9 \text { per cent }) \\
4531-4418(94.5 \text { per cent })\end{array}$ \\
\hline KGZ15-C05 & CKR & 073.5589 & 42.2104 & 2448 & 150 & bulk, dark clay & $5260 \pm 30$ & $\begin{array}{l}6249-6149(12.5 \text { per cent }) \\
6121-6039(31.5 \text { per cent }) \\
6033-5935(51.4 \text { per cent })\end{array}$ \\
\hline KGZ15-C07 & CKR & 073.5589 & 42.2104 & 2448 & 130 & charcoal & $4820 \pm 30$ & $\begin{array}{c}5606-5576(34.8 \text { per cent }) \\
5548-5476(60.6 \text { per cent })\end{array}$ \\
\hline
\end{tabular}

\section{DISCUSSION}

Our results have confirmed that the ruptures from the $1992 \mathrm{Su}-$ usamyr earthquake were fragmented and were short given the magnitude of their offset. We have shown that the western ruptures that had been mapped as $3.4 \mathrm{~km}$ in length (Ghose et al. 1997) were even shorter, at $2.0 \mathrm{~km}$, but we have also found that those ruptures in the west were part of a longer, disjointed series of fresh scarps which in total spans almost $12 \mathrm{~km}$ where the slip reached, or presumably nearly reached, the surface. At the M41 highway rupture in the east a large proportion of the slip that would be expected for an $M_{\mathrm{w}} 7.2$ earthquake based on scaling relationships — at least $3.6 \pm 0.1 \mathrm{~m}-$ did reach the surface but, even including our new observations, we are left with an unruptured gap of $>20 \mathrm{~km}$ in the area that experienced some of the strongest shaking and which is directly updip of the plane defined by the aftershocks (Ghose et al. 1997; Mellors et al. 1997). 
Table 3. Luminescence dating results from the Chet-Korumdy trench. Uncertainties are standard error. Longitude $073.5589^{\circ} \mathrm{E}$, latitude $42.2104^{\circ} \mathrm{N}$, elevation $2448 \mathrm{~m}$. OD = overdispersion parameter (Galbraith et al. 1999). The ages for KGZ15-L02 and KGZ15-L03, but not KGZ15-L01, are fading corrected (Section 3.2). Total usable aliquots refer to the total number of usable aliquots before outlier removal. The skewness parameter was calculated following Bailey \& Arnold (2006). Uncertainties on the ages are one sigma.

\begin{tabular}{|c|c|c|c|c|c|c|c|}
\hline Sample & $\begin{array}{l}\text { Depth } \\
\text { (m) }\end{array}$ & $\begin{array}{l}\text { Total dose rate } \\
\quad\left(\mathrm{Gy} \mathrm{ka}^{-1}\right)\end{array}$ & $\begin{array}{l}\text { Acceptable } \\
\text { aliquots(total } \\
\text { analysed) }\end{array}$ & $\begin{array}{c}\text { OD } \\
\text { (per cent) }\end{array}$ & Skew in $\mathrm{D}_{\mathrm{e}}$ & $\begin{array}{l}\text { CAM D }_{\mathrm{e}} \\
\text { pIRIR } 225- \\
\text { following outlier } \\
\text { removal } \\
(\mathrm{Gy})\end{array}$ & $\begin{array}{c}\mathrm{pIRIR}_{225} \text { age } \\
\quad(\mathrm{ka})\end{array}$ \\
\hline KGZ15-L01 & 0.55 & $8.24 \pm 0.32$ & $16(18)$ & $24 \pm 4$ & $1.5 \pm 0.6$ & $24.6 \pm 1.2$ & $3.0 \pm 0.2$ \\
\hline KGZ15-L02 & 0.80 & $8.13 \pm 0.30$ & $16(18)$ & $19 \pm 3$ & $1.4 \pm 0.6$ & $20.1 \pm 0.9$ & $3.0 \pm 0.1$ \\
\hline KGZ15-L03 & 0.60 & $7.63 \pm 0.30$ & $19(21)$ & $22 \pm 3$ & $2.2 \pm 0.5$ & $21.1 \pm 0.9$ & $3.5 \pm 0.2$ \\
\hline
\end{tabular}

We cannot rule out the possibility that the two sets of ruptures are the result of two different earthquakes. It is possible that the western surface ruptures are the result of the $M_{s} 6.6$ aftershock rather than the main shock. In that case, we would still have the difficult task of explaining why the sole rupture from the $M_{\mathrm{w}} 7.2$ main shock hosted a significant fraction of the slip expected for an earthquake of that magnitude but was only $\leq 600 \mathrm{~m}$ long. Even for this modern earthquake sequence, because the main shock and aftershock were so close together in time, we cannot distinguish between their surface ruptures, so we must treat them as one event for the purposes of comparison to the palaeoseismic record.

Based solely on the 1992 ruptures, we could suggest that the earthquake only broke the surface at points where the fault trace runs along the base of bedrock-cored mountains, and that where deformation has migrated away from the range-front, the nearsurface fault slip was accommodated in the basin fill via folding. Although that conclusion fits our observations from the most recent event, it does not tally with our observations from prehistoric earthquake ruptures. In Section 5 we showed two sites where prehistoric earthquakes have ruptured the surface alongside folds. Our trenches through these scarps show no evidence for slip in the 1992 earthquake. The fault tip does, therefore, reach the surface, but reactivation of the breakthrough fault seems to be intermittent.

Fig. 15 highlights the challenges for interpretation of earthquake histories in areas such as Suusamyr. The fault does not rupture completely new scarps with every earthquake-our results show that the Cholgondysai, Dzhalpaksu and CKR scarps have all ruptured at least twice - but palaeoseismic investigations at any of the sites individually would reveal different earthquake histories. The scarps are all shorter than the tens of kilometres subsurface width that is expected of a surface-rupturing earthquake and much shorter than the $50 \pm 10 \mathrm{~km}$ estimated fault width for the 1992 earthquake. Burial or erosion of scarps certainly contributes to the discontinuity of ruptures, however our observations here indicate that significant discontinuity can be inherent to the tectonic ruptures. Both phenomena are most obvious at the M41 highway rupture where the ruptures crossing the river were eroded within months by the powerful river, but the scarp height distribution we have measured shows real taper to zero within hundreds of metres. Burial and erosion are ubiquitous processes that need to be considered for palaeoseismic studies everywhere; our observations additionally suggest that, like the 1992 ruptures, the prehistoric ruptures were already fragmented at their creation (Sections 4.2 and 5.2).

The established practice of applying scaling relationships to studies of prehistoric earthquakes presumes that surface ruptures and offsets are representative of fault parameters at depth. Indeed, among reverse-faulting earthquakes there are examples for which the surface expression agrees strongly with the slip at depth, including the 1988 Tennant Creek, Australia (Bowman 1992), 1999 ChiChi, Taiwan (Ji et al. 2001; Lee et al. 2003), 2005 Kashmir, Pakistan (Avouac et al. 2006; Kaneda et al. 2008), and 2008 Wenchuan, China (Lin et al. 2009; Xu et al. 2009) earthquakes. However, the scatter in the surface rupture length- and (particularly) displacementmagnitude relationships for reverse faulting earthquakes (Wells \& Coppersmith 1994; Moss \& Ross 2011) attests to the great range in their behaviour and surface expression.

It is already known that many earthquakes do not produce primary surface rupture (i.e. are blind) (e.g. Stein \& King 1984; Lin \& Stein 1989; Stein \& Yeats 1989; Lettis et al. 1997), and that for a given magnitude, more reverse earthquakes than strike-slip or normal earthquakes fail to produce surface rupture (Moss \& Ross 2011). Failure for slip to reach the surface is usually attributed to a portion of the shallow slip being accommodated by folding, or to the majority of the coseismic slip being at depth (e.g. Stein \& King 1984; Lin \& Stein 1989; Walker et al. 2005; Grandin et al. 2015).

There are two scenarios that involve slip partially reaching the surface at ruptures. The first is that an earthquake produces surface breaks of some kind over a long distance but they have smaller average displacement than expected for their moment magnitude. This has been seen for earthquakes such as the 1962 Ipak, Iran (Ambraseys 1963; Berberian 1981) and 2002 Changrueh (Avaj), Iran (Walker et al. 2005) earthquakes, and is compatible with the explanations above. The 1992 Suusamyr earthquake shows the opposite phenomenon, in that the displacement of the surface ruptures is roughly consistent with what is expected from the earthquake's magnitude according to scaling laws (Thingbaijam et al. 2017), but the ruptures are short and separated by a gap that is longer than their total length. Earthquakes that have shown large gaps between segments of surface ruptures are not unheard of. The 1952 Kern County, California, USA earthquake was an oblique earthquake which caused surface ruptures on either side of the San Joaquin Valley but was blind beneath the valley itself (Buwalda \& St.Amand 1955; Bawden 2001). The 2005 Dahuiyeh (Zarand), Iran earthquake reached the surface where bedding was planar and subparallel to the fault but not where bedding was folded and the bedding was oblique to the rupture plane (Talebian et al. 2006). Neither showed such high displacement-to-length ratios as the eastern segment at Suusamyr.

In both the Kern county and Dahuiyeh cases, structural or lithological controls had an important influence on the pattern of surface rupture, but obtaining information about several earthquakes on the Suusamyr Fault allows us to take our understanding further. The 1992 Suusamyr earthquake had superficially straightforward kinematics - its mechanism is as expected for the region, there is no need to model the seismograms using subevents and it was a major earthquake that ruptured most or all of the seismogenic layer 

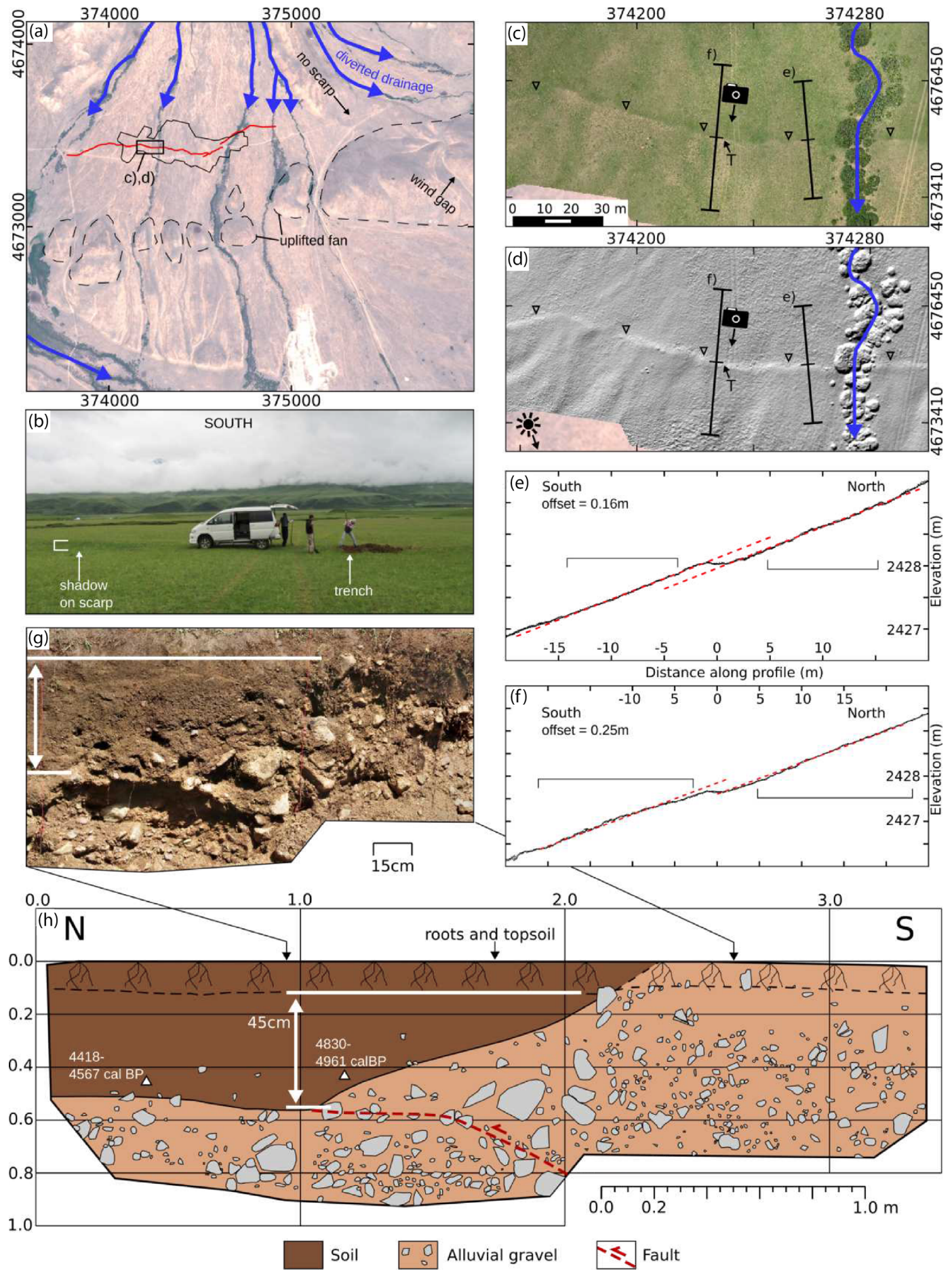

Figure 14. (a) Pléiades imagery of the Turabulak site, location shown in Fig. 1. Red line shows the scarp, black solid line marks the extent of our UAV DEM. (b) A photograph of the scarp and trench site. The scarp is picked out by a slight shadow running from left to right. (c) UAV orthophoto of the scarp, black triangles mark the scarp, T shows trench site, camera shows the viewpoint of panel (b). (d) Hillshaded $10 \mathrm{~cm}$ DEM of the same area. (e) A typical topographic profile. The best-fit lines are shown in dashed red and the sections of the profile that they were fitted to are marked. (f) As panel (e) but for a location across the trench site. (g) Photomosaic of the central portion of the east wall of the trench, showing the top of the gravel layer displaced by $\sim 45 \mathrm{~cm}$ and the resulting uphill-facing escarpment partially filled by brown soil. (h) Trench log of the east wall. The scale and the location of the white markings are exactly as in panel (g).

(Mellors et al. 1997; Ghose et al. 1998; Sloan et al. 2011). As we have discussed, it is plausible that the presence or absence of folds at the near-surface had an influence on the pattern of the 1992 earthquake, but the variability in rupture pattern that we have found between the 1992 and prehistoric earthquakes that we have found shows that there is also an inherent variability. This makes Suusamyr an important example for reverse fault palaeoseismology in general. Although structure could reasonably be expected to be 


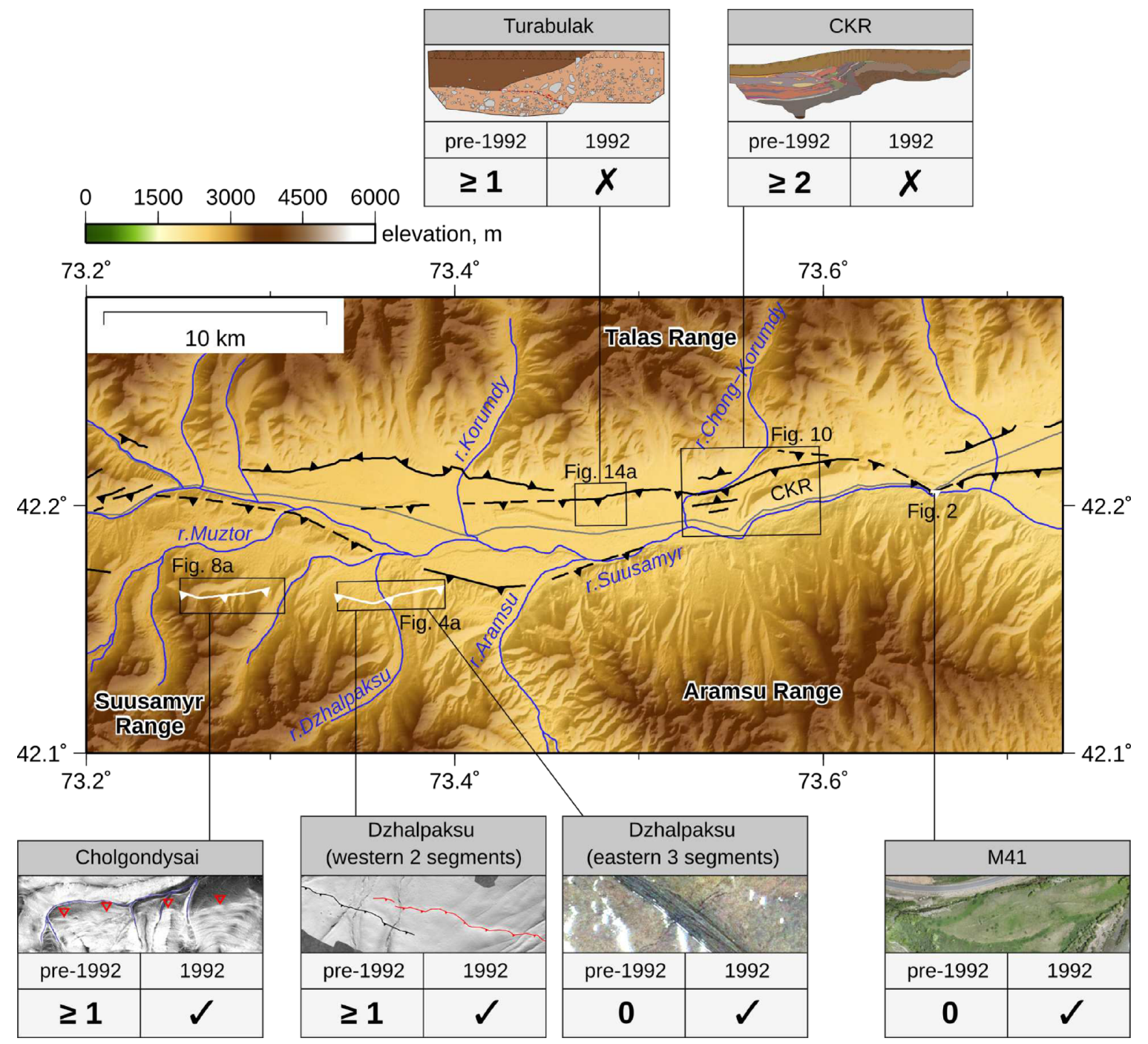

Figure 15. Summary of the evidence for surface rupturing earthquakes at each of our sites. The key for the main panel is as in Fig. 1 .

constant over the timescale of several earthquake cycles and to produce similar results, in the Suusamyr case the earthquake record cannot be captured without analysis at multiple sites.

\section{CONCLUSIONS}

We used satellite imagery, DEMs and field investigations to map and measure surface ruptures from the 1992 Suusamyr earthquake and prehistoric earthquakes on the Suusamyr Fault. There is evidence for a total length of up to $7.6 \mathrm{~km}$ of fresh surface ruptures from the 1992 Suusamyr earthquake - a value longer than previously thought but still much shorter than the subsurface rupture length as estimated from the aftershock extent or from scaling relationships given the earthquake's magnitude. The ruptures were discontinuous, with the western $7 \mathrm{~km}$ of ruptures being made up of six segments that are spread across $12 \mathrm{~km}$ and the eastern, $0.6 \mathrm{~km}$-long rupture segment separated from the western ruptures by a gap of $>20 \mathrm{~km}$. At least three of the rupture sections from 1992 were on pre-existing fault scarps, but we have also identified additional active fault scarps that did not rupture in the 1992 earthquake despite being situated in the gap between the 1992 ruptures. By trenching at two sites on those scarps we have compiled a palaeoseismic record for the fault that shows a minimum of three surface-rupturing earthquakes within the past $\sim \geq 8 \mathrm{kyr}$, but our mapping also shows that the fault scarps are short, discontinuous and reoccupied in an erratic manner. No single section of fault scarp carries a full record of the earthquake history and, although there is abundant evidence for tectonic shortening along the valley, there is no continuous scarp or fold along which single trenches or standard empirical scaling relationships could be applied to recognise the history of $M>6$ earthquakes.

Our results update and add to a valuable example of surfacerupturing earthquakes in the Tien Shan. They also demonstrate that reverse faulting earthquakes can have variability beyond what can be explained by structural geology or near-surface lithology alone, and highlight the importance of investigating as many sites as possible for studies that aim to establish the seismic history of a fault.

\section{ACKNOWLEDGEMENTS}

We thank Martin Mai, the Editor, and Robert Mellors and Matthieu Alexis Ferry for their constructive reviews which improved the manuscript. This study has benefited from funding from the Centre for Observation and Modelling of Earthquakes, Volcanoes and 
Tectonics (COMET, GA/13/M/031) and Looking inside the Continents from Space (LiCS) (NE/K011006/1). Fieldwork and dating were supported by the NERC-ESRC Earthquakes without Frontiers (EwF) consortium (Increasing Resilience to Natural Hazards theme, EwF_NE/J02001X/1_1). EAA was supported by an NERC studentship in the Oxford Environmental Research Doctoral Training Partnership (NE/L0021612/1). We thank Azat Moldobaev for help in the field and Ainagul and Sagan for their help with field logistics. The CORONA images and SRTM data are available from the U.S. Geological Survey https://earthexplorer.usgs.gov. The AW3D30 data are copyright of JAXA and are freely available from http://www.eorc.jaxa.jp/ALOS/en/aw3d30/. The data for DEMs that were made using UAV photographs will shortly be uploaded to the OpenTopography Facility https://opentopography.org

\section{REFERENCES}

Abdrakhmatov, K.E. et al., 2016. Multisegment rupture in the 11 July 1889 Chilik earthquake $\left(M_{\mathrm{w}} 8.0-8.3\right)$, Kazakh Tien Shan, interpreted from remote sensing, field survey, and paleoseismic trenching, J. geophys. Res., 121(6), 4615-4640.

Aitken, M.J., 1985. Thermoluminescence dating, Studies in archaeological science,. Academic Press.

Ambraseys, N.N., 1963. The Buyin-Zara (Iran) earthquake of September, 1962 a field report, Bull. Seism. Soc. Am., 53(4), 705-740.

Anderson, J.G., Biasi, G.P. \& Wesnousky, S.G., 2017. Fault scaling relationships depend on the average fault slip rate, Bull. Seism. Soc. Am., 107(6), 2561-2577.

Arnold, L.J., Bailey, R.M. \& Tucker, G.E., 2007. Statistical treatment of fluvial dose distributions from southern Colorado arroyo deposits, Quat. Geochronol., 2(1), 162-167.

Avouac, J.-P., Ayoub, F., Leprince, S., Konca, O. \& Helmberger, D., 2006. The $2005, M_{\mathrm{w}} 7.6$ Kashmir earthquake: sub-pixel correlation of ASTER images and seismic waveforms analysis, Earth Planet. Sci. Lett., 249(3-4), 514-528.

Bailey, R.M. \& Arnold, L.J., 2006. Statistical modelling of single grain quartz De distributions and an assessment of procedures for estimating burial dose, Quat. Sci. Rev., 25(19), 2475-2502.

Bawden, G.W., 2001. Source parameters for the 1952 Kern County earthquake, California: a joint inversion of leveling and triangulation observations, J. geophys. Res., 106(B1), 771-785.

Berberian, M., 1981. Active faulting and tectonics of Iran, Vol. 3, pp. $33-$ 69, in eds Gupta, H.K. \& Delany, F.M., Zagros-Hindu Kush-Himalaya Geodynamic Evolution, American Geophysical Union.

Biasi, G.P. \& Weldon, R.J., 2006. Estimating surface rupture length and magnitude of paleoearthquakes from point measurements of rupture displacement, Bull. seism. Soc. Am., 96(5), 1612-1623.

Bindi, D., Abdrakhmatov, K., Parolai, S., Mucciarelli, M., Grünthal, G., Ischuk, A., Mikhailova, N. \& Zschau, J., 2012. Seismic hazard assessment in Central Asia: Outcomes from a site approach, Soil Dyn. Earthq. Eng., 37, 84-91.

Blong, R.J. \& Gillespie, R., 1978. Fluvially transported charcoal gives erroneous 14c ages for recent deposits, Nature, 271(5647), 739-741.

Bogachkin, B. et al., 1997. The structure of the 1992 Susamyr earthquake source based on its geological and seismological manifestations, Izv. Phys. Solid Earth, 33(11), 867-882.

Bowman, J.R., 1992. The 1988 Tennant Creek, northern territory, earthquakes: a synthesis, Aust. J. Earth Sci., 39(5), 651-669.

Bronk Ramsey, C., 2009. Bayesian analysis of radiocarbon dates, Radiocarbon, 51(1), 337-360.

Buwalda, J.P. \& St.Amand, P., 1955. Geological effects of the ArvinTehachapi earthquake, in Earthquakes in Kern County California during 1952, ed. Oakeshott, G.B., California Div Mines Bull., 171, 41-56.
Buylaert, J.P., Murray, A.S., Thomsen, K.J. \& Jain, M., 2009. Testing the potential of an elevated temperature IRSL signal from K-feldspar, Radiat. Meas., 44(5), 560-565.

Chediya, O.K., Mikhel, G. \& Mikhaylyov, V., 1997. On rates of Holocene tectonic movements and an attempt to determine the duration of seismic calm in the central Tien Shan (in Russian), Echo Sci. Proc. Nat. Acad. Sci. Kyrgyz Republic(1), 13-17.

Deev, E.V. et al., 2016. Paleoseismological and archaeoseismological data from the western AlabashKonurolen intramontane basin (southern Lake Issyk Kul area, Kyrgyzstan), Russ. Geol. Geophys., 57(7), 1090-1098.

Farr, T.G. et al., 2007. The Shuttle Radar Topography Mission, Rev. Geophys., 45(2).

Field, E.H. et al., 2014. Uniform California Earthquake Rupture Forecast, Version 3 (UCERF3) - the time-independent model, Bull. seism. Soc. Am., 104(3), 1122-1180.

Galbraith, R.F., Roberts, R.G., Laslett, G.M., Yoshida, H. \& Olley, J.M., 1999. Optical dating of single and multiple grains of quartz from Jinmium Rock Shelter, Northern Australia: Part I, experimental design and statistical models, Archaeometry, 41(2), 339-364.

Ghose, S. et al., 1997. The $M_{\mathrm{S}}=7.31992$ Suusamyr, Kyrgyzstan, earthquake in the Tien Shan: 2. Aftershock focal mechanisms and surface deformation, Bull. seism. Soc. Am., 87(1), 23-38.

Ghose, S., Hamburger, M. \& Ammon, C., 1998. Source parameters of moderate-sized earthquakes in the Tien Shan, central Asia from regional moment tensor inversion, Geophys. Res. Lett., 25(16), 3181-3184.

Gómez, J.M., Bukchin, B., Madariaga, R., Rogozhin, E.A. \& Bogachkin, B., 1997. Rupture process of the 19 August 1992 Susamyr, Kyrgyzstan, earthquake, J. Seismol., 1(3), 219-235.

Grandin, R., Vallée, M., Satriano, C., Lacassin, R., Klinger, Y., Simoes, M. \& Bollinger, L., 2015. Rupture process of the $M_{\mathrm{W}}=7.92015$ Gorkha earthquake (Nepal): Insights into Himalayan megathrust segmentation, Geophys. Res. Lett., 42(20), 8373-8382.

Grützner, C. et al., 2017. Assessing the activity of faults in continental interiors: palaeoseismic insights from SE Kazakhstan, Earth planet. Sci. Lett., 459, 93-104.

Guérin, G., Mercier, N. \& Adamiec, G., 2011. Dose-rate conversion factors: update, Ancient TL, 29, 5-8.

Hemphill-Haley, M.A. \& Weldon, R.J., 1999. Estimating prehistoric earthquake magnitude from point measurements of surface rupture, Bull. seism. Soc. Am., 89(5), 1264-1279.

Huntley, D. \& Baril, M., 1997. The K content of the K-feldspars being in measured in optical and thermoluminescence dating, Ancient TL, 15, $11-13$.

Huntley, D. \& Hancock, R., 2001. The Rb contents of the K-feldspar grains being measured in optical dating, Ancient TL, 19, 43-46.

Huntley, D.J. \& Lamothe, M., 2001. Ubiquity of anomalous fading in Kfeldspars and the measurement and correction for it in optical dating, Can. J. Earth Sci., 38(7), 1093-1106.

James, M.R. \& Robson, S., 2014. Mitigating systematic error in topographic models derived from UAV and ground-based image networks, Earth Surf. Process. Landf., 39(10), 1413-1420.

Ji, C., Helmberger, D.V., Song, T.-R.A., Ma, K.-F. \& Wald, D.J., 2001. Slip distribution and tectonic implication of the 1999 Chi-Chi, Taiwan, Earthquake, Geophys. Res. Lett., 28(23), 4379-4382.

Kalmetieva, Z., Mikolaichuk, A., Moldobekov, B., Meleshko, A., Jantaev, M., Zubovich, A. \& Havenith, H.-B., 2009. Atlas of Earthquakes in Kyrgyzstan, Central-Asian Institute for Applied Geosciences and United Nations International Strategy for Disaster Reduction Secretariat Office in Central Asia, Bishkek.

Kaneda, H. et al., 2008. Surface rupture of the 2005 Kashmir, Pakistan, earthquake and its active tectonic implications, Bull. seism. Soc. Am., 98(2), 521-557.

Kondorskaya, N.V., Shebalin, N.V., Khrometskaya, Y.A. \& Gvishiani, A.D., 1982. New Catalog of Strong Earthquakes in the USSR from Ancient Times through 1977, translated and published by, World Data Center A for Solid Earth Geophysics. 
Korjenkov, A., Bowman, D., Haselton, K. \& Porat, N., 1999. Recent drainage diversions under thrusting conditions in the Suusamyr Valley, the Tien Shan Range, Kyrgyzstan, Isr. J. Earth Sci., 48(2), 63-79.

Krüger, F., Kulikova, G. \& Landgraf, A., 2015. Instrumental magnitude constraints for the 11 July 1889, Chilik earthquake, Geol. Soc., London, Spec. Publ., 432, 41-72.

Kulikova, G. \& Krüger, F., 2015. Source process of the 1911 M8.0 ChonKemin earthquake: investigation results by analogue seismic records, Geophys. J. Int., 201(3), 1891-1911.

Kulikova, G. \& Krüger, F., 2017. Historical seismogram reproductions for the source parameters determination of the 1902, Atushi (Kashgar) earthquake, J. Seismol., 21(6), 1577-1597.

Landgraf, A. et al., 2016. Repeated large-magnitude earthquakes in a tectonically active, low-strain continental interior: The northern Tien Shan, Kyrgyzstan, J. geophys. Res., 121(5), 3888-3910.

Lee, Y.-H., Hsieh, M.-L., Lu, S.-D., Shih, T.-S., Wu, W.-Y., Sugiyama, Y., Azuma, T. \& Kariya, Y., 2003. Slip vectors of the surface rupture of the 1999 Chi-Chi earthquake, western Taiwan, J. Struct. Geol., 25(11), $1917-1931$.

Leonard, M., 2010. Earthquake fault scaling: self-consistent relating of rupture length, width, average displacement, and moment release, Bull. seism. Soc. Am., 100(5A), 1971-1988.

Lettis, W.R., Wells, D.L. \& Baldwin, J.N., 1997. Empirical observations regarding reverse earthquakes, blind thrust faults, and quaternary deformation: are blind thrust faults truly blind? Bull. seism. Soc. Am., 87(5), 1171-1198.

Lin, A., Ren, Z., Jia, D. \& Wu, X., 2009. Co-seismic thrusting rupture and slip distribution produced by the $2008 M_{\mathrm{w}} 7.9$ Wenchuan earthquake, China, Tectonophysics, 471(3), 203-215.

Lin, J. \& Stein, R., 1989. Coseismic folding, earthquake recurrence, and the 1987 source mechanism at Whittier Narrows, Los Angeles basin, California, J. geophys. Res., 94(B7), 9614-9632.

Mackenzie, D. \& Elliott, A., 2017. Untangling tectonic slip from the potentially misleading effects of landform geometry, Geosphere, 13(4), 13101328.

Mai, P.M. \& Beroza, G.C., 2000. Source scaling properties from finite-faultrupture models, Bull. seism. Soc. Am., 90(3), 604-615.

Medialdea, A., Thomsen, K.J., Murray, A.S. \& Benito, G., 2014. Reliability of equivalent-dose determination and age-models in the OSL dating of historical and modern palaeoflood sediments, Quat. Geochronology, 22, $11-24$.

Mejdahl, V., 1979. Thermoluminescence dating: beta-dose attenuation in quartz grains, Archaeometry, 21(1), 61-72.

Mellors, R.J., Vernon, F.L., Pavlis, G.L., Abers, G.A., Hamburger, M.W., Ghose, S. \& Iliasov, B., 1997. The $M_{\mathrm{s}}=7.31992$ Suusamyr, Kyrgyzstan, earthquake: 1. Constraints on fault geometry and source parameters based on aftershocks and body-wave modeling, Bull. seism. Soc. Am., 87(1), 1122.

Middleton, T.A., Walker, R.T., Parsons, B., Lei, Q., Zhou, Y. \& Ren, Z., 2015. A major, intraplate, normal-faulting earthquake: the 1739 Yinchuan event in northern China, J. geophys. Res., p. 293-320.

Moss, R. E.S. \& Ross, Z.E., 2011. Probabilistic fault displacement hazard analysis for reverse faults, Bull. seism. Soc. Am., 101(4), 1542-1553.

Murray, A.S. \& Wintle, A.G., 2000. Luminescence dating of quartz using an improved single-aliquot regenerative-dose protocol, Radiat. Meas., 32(1), $57-73$.

Olley, J., Caitcheon, G. \& Murray, A., 1998. The distribution of apparent dose as determined by optically stimulated luminescence in small aliquots of fluvial quartz: implications for dating young sediments, Quat. Sci. Rev., 17(11), 1033-1040.

Patyniak, M. et al., 2017. Paleoseismic record of three Holocene earthquakes rupturing the Issyk Ata Fault near Bishkek, North Kyrgyzstan, Bull. seism. Soc. Am., 107(6), 2721-2737.

Petersen, M.D. et al., 2015. The 2014 United States National Seismic Hazard Model, Earthq. Spectra, 31(S1), S1-S30.

Prescott, J.R. \& Hutton, J.T., 1994. Cosmic ray contributions to dose rates for luminescence and ESR dating: Large depths and long-term time variations, Radiat. Meas., 23(2), 497-500.
Readhead, M., 2002. Absorbed dose fraction for 87rb beta particles, Ancient $T L, 20,25-29$.

Reimer, P.J. et al., 2013. IntCal13 and Marine13 Radiocarbon Age Calibration Curves 0-50,000 Years cal BP, Radiocarbon, 55(4), 1869-1887.

Schiffer, M.B., 1986. Radiocarbon dating and the old woodproblem: The case of the Hohokam chronology, J. Archaeological Sci., 13(1), 13-30.

Sloan, R.A., Jackson, J.A., McKenzie, D. \& Priestley, K., 2011. Earthquake depth distributions in central Asia, and their relations with lithosphere thickness, shortening and extension, Geophys. J. Int., 185(1), 1-29.

Stein, R. \& King, G., 1984. Seismic potential revealed by surface folding: 1983 Coalinga, California, earthquake, Science, 224(4648), 869-872.

Stein, R.S. \& Yeats, R.S., 1989. Hidden Earthquakes, Sci. Am., 260(6), $48-59$.

Stirling, M., Goded, T., Berryman, K. \& Litchfield, N., 2013. Selection of earthquake scaling relationships for seismic hazard analysis, Bull. seism. Soc. Am., 103(6), 2993-3011.

Takaku, J., Tadono, T. \& Tsutsui, K., 2014. Generation of high resolution global DSM from ALOS PRISM, Int. Arch. Photogramm. Remote Sens. Spatial Inf. Sci., 40, 243-248.

Talebian, M. et al., 2006. The Dahuiyeh (Zarand) earthquake of 2005 February 22 in central Iran: reactivation of an intramountain reverse fault, Geophys. J. Int., 164(1), 137-148.

Thingbaijam, K. K.S., Mai, P.M. \& Goda, K., 2017. New empirical earthquake source-scaling laws, Bull. seism. Soc. Am., 107(5), 2225-2246.

Thompson, S.C., Weldon, R.J., Rubin, C.M., Abdrakhmatov, K., Molnar, P. \& Berger, G.W., 2002. Late Quaternary slip rates across the central Tien Shan, Kyrgyzstan, central Asia, Geophys. J. Res., 107(B9), 2203.

Thomsen, K.J., Murray, A.S., Jain, M. \& Btter-Jensen, L., 2008. Laboratory fading rates of various luminescence signals from feldspar-rich sediment extracts, Radiat. Meas., 43(9), 1474-1486.

Walker, R.T., Bergman, E., Jackson, J., Ghorashi, M. \& Talebian, M., 2005. The 2002 June 22 Changureh (Avaj) earthquake in Qazvin province, northwest Iran: epicentral relocation, source parameters, surface deformation and geomorphology, Geophys. J. Int., 160(2), 707-720.

Wells, D. \& Coppersmith, K., 1994. New empirical relationships among magnitude, rupture length, rupture width, rupture area, and surface displacement, Bull. seism. Soc. Am., 84(4), 974-1002.

Westoby, M.J., Brasington, J., Glasser, N.F., Hambrey, M.J. \& Reynolds, J.M., 2012. Structure-from-Motion photogrammetry: a low-cost, effective tool for geoscience applications, Geomorphology, 179, 300-314.

Xu, X., Wen, X., Yu, G., Chen, G., Klinger, Y., Hubbard, J. \& Shaw, J., 2009. Coseismic reverse- and oblique-slip surface faulting generated by the $2008 M_{\mathrm{W}} 7.9$ Wenchuan earthquake, China, Geology, 37(6), 515-518.

Youngs, R.R. et al., 2003. A methodology for probabilistic fault displacement hazard analysis (PFDHA), Earthq. Spectra, 19(1), 191-219.

Zhou, Y., Parsons, B., Elliott, J.R., Barisin, I. \& Walker, R.T., 2015. Assessing the ability of Pleiades stereo imagery to determine height changes in earthquakes: a case study for the El Mayor-Cucapah epicentral area, $J$. geophys. Res., 120(12), 8793-8808.

Zubovich, A.V. et al., 2010. GPS velocity field for the Tien Shan and surrounding regions, Tectonics, 29(6), TC6014.

\section{SUPPORTING INFORMATION}

Supplementary data are available at $G J I$ online.

\section{supp_info_ruptures.kml supp_table_scarp_heights.txt}

Please note: Oxford University Press is not responsible for the content or functionality of any supporting materials supplied by the authors. Any queries (other than missing material) should be directed to the corresponding author for the article. 


\section{APPENDIX A: FURTHER DETAILS ON THE LUMINESCENCE DATING METHODOLOGY}

The environmental dose rates of the samples were estimated as follows. The total uranium, thorium and potassium contents of the samples were determined from subsamples of the sampling tubes using inductively coupled plasma mass spectrometry, carried out at the University of Leicester. Elemental concentrations were converted to dose rates using the conversion factors of Guérin et al. (2011), with appropriate adjustment for grain size (Mejdahl 1979; Readhead 2002) and sample water content (Aitken 1985). Dose rates for internal $K$ and $R b$ were based on the assumption of $\mathrm{K}$ feldspar grain $K$ and $R b$ concentrations of $12.5 \pm 0.5$ per cent and $400 \pm 100$ ppm, respectively (Huntley \& Baril 1997; Huntley \& Hancock 2001). It was assumed that the as-measured water content was appropriate, and a 2 per cent (absolute) uncertainty in water content was propagated into the final dose rate uncertainties. It is assumed that the dose rate remained constant for the duration of burial. Cosmic dose rates were determined following Prescott \& Hutton (1994) and were based on the current sample burial depth. Details of the various calculated dose rate components are shown in Table A1.

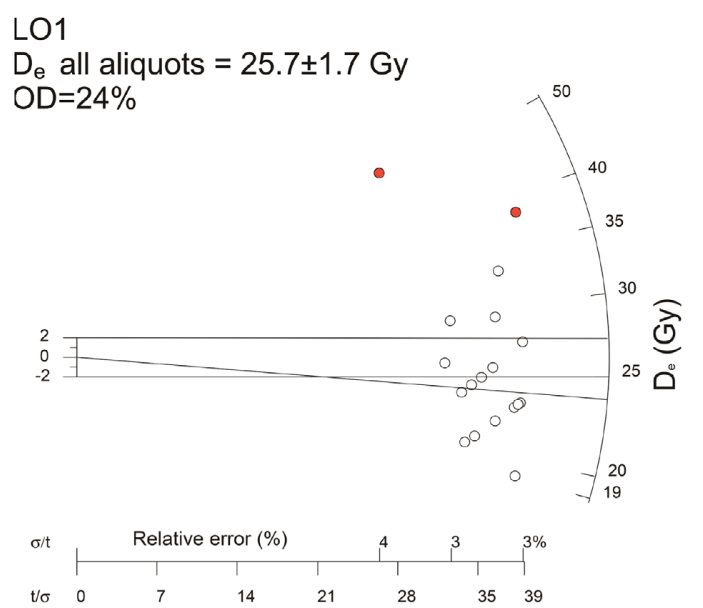

LO2
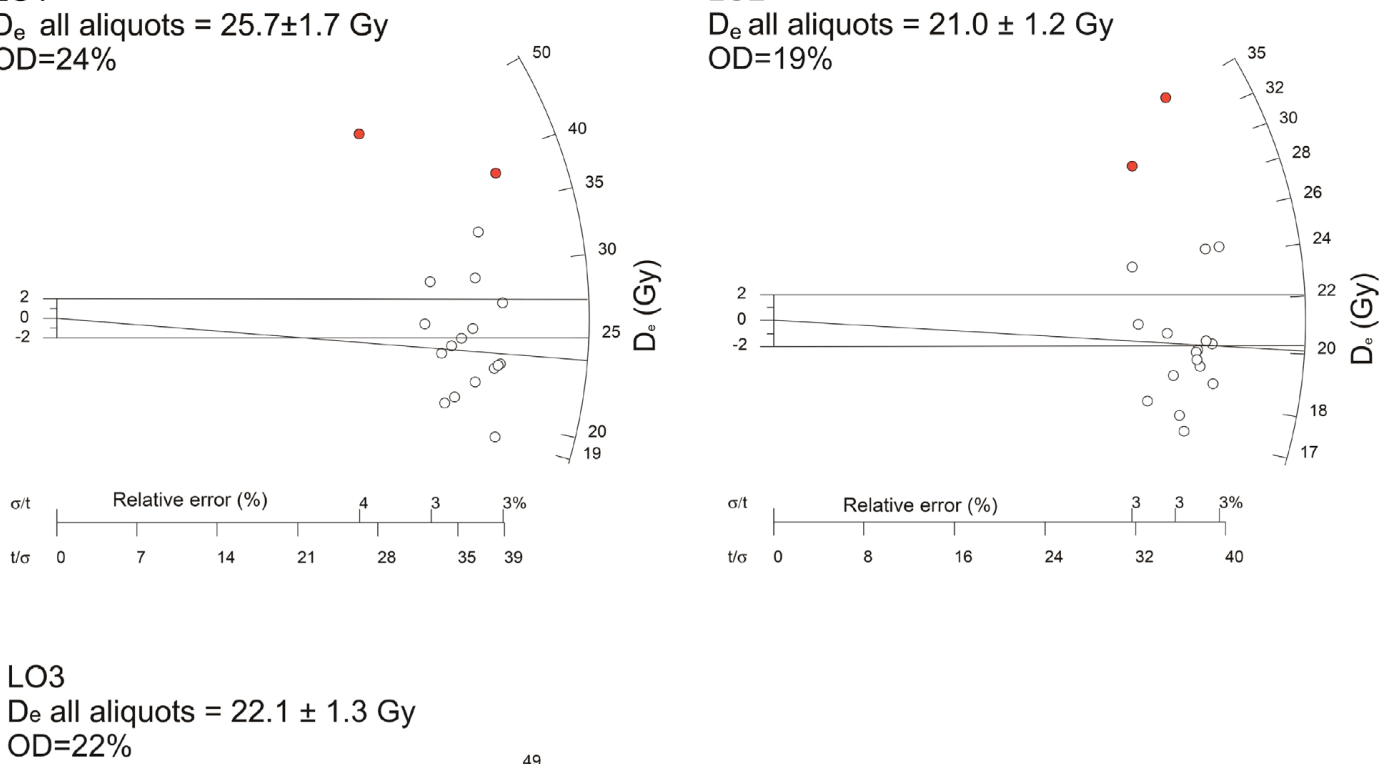

$\mathrm{OD}=22 \%$

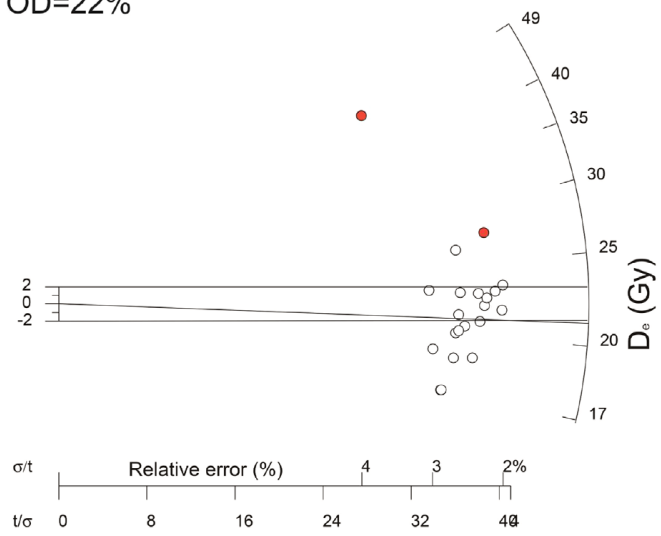

Figure A1. Radial plots showing the distribution in equivalent doses for the pIRIR 225 analysis of the samples LO1-LO3. The plots show all measured aliquots and are centred ( 2 horizontal bars) on the Central Age $\mathrm{D}_{\mathrm{e}}$ for all aliquots. The identified outlier aliquots are shown in red and the resulting mean $\mathrm{D}_{\mathrm{e}}$ following their removal (Table 3) is shown with the additional marker line. The central age mean and overdispersion parameter for all measured aliquots are also shown.

Table A1. Details of the sample dose rate determinations. Elemental concentrations were obtained using ICP-MS, with associated relative uncertainties (derived from replicate measurements using this method) of 10 per cent assigned to $U$ and $T h$ and 5 per cent assigned to $K$. These were propagated to the final dose rate determination along with an (absolute) water content uncertainty of \pm 2 per cent. The measured grain size range was $212-250 \mu \mathrm{m}$.

\begin{tabular}{lcccccccccc}
\hline Sample & $\begin{array}{c}\text { Water } \\
(\text { per cent })\end{array}$ & $\begin{array}{c}\text { Depth } \\
(\mathrm{m})\end{array}$ & $\begin{array}{c}U \\
(\mathrm{ppm})\end{array}$ & $\begin{array}{c}\text { Th } \\
(\mathrm{ppm})\end{array}$ & $\begin{array}{c}K \\
\left(\mathrm{per} \mathrm{cent}^{2}\right.\end{array}$ & $\begin{array}{c}\text { Beta (ext) } \\
\left(\mathrm{mGy} \mathrm{a}^{-1}\right)\end{array}$ & $\begin{array}{c}\text { Beta (int) } \\
\left(\mathrm{mGy} \mathrm{a}^{-1}\right)\end{array}$ & $\begin{array}{c}\text { Gamma } \\
\left(\mathrm{mGy} \mathrm{a}^{-1}\right)\end{array}$ & $\begin{array}{c}\text { Total Cosmic } \\
\left(\mathrm{mGy} \mathrm{a}^{-1}\right)\end{array}$ & $\begin{array}{c}\text { Total dose rate } \\
\left(\mathrm{Gy} \mathrm{ka}^{-1}\right)\end{array}$ \\
\hline KGZ15-L01 & 10.3 & 0.55 & 13.7 & 28.8 & 3.1 & $3659 \pm 227$ & $986 \pm 68$ & $3287 \pm 209$ & $310 \pm 16$ & $8.24 \pm 0.32$ \\
KGZ15-L02 & 8.2 & 0.80 & 11.4 & 25.9 & 3.5 & $3739 \pm 228$ & $986 \pm 68$ & $3104 \pm 188$ & $300 \pm 15$ & $8.13 \pm 0.30$ \\
KGZ15-L03 & 14.4 & 0.60 & 13.3 & 25.8 & 3.0 & $3362 \pm 209$ & $986 \pm 68$ & $2973 \pm 188$ & $308 \pm 15$ & $7.63 \pm 0.30$ \\
\hline
\end{tabular}

